Supporting Information

\title{
Stable Isotopic Labeling and Nontarget Identification of Nanogram/Liter Amino
}

\section{Contaminants in Water}

Zhongshan Liu, ${ }^{\dagger}$ Caley B. Craven, ${ }^{\ddagger}$ Guang Huang, ${ }^{\dagger}$ Ping Jiang, ${ }^{\dagger}$ Di Wu, ${ }^{\dagger}$ Xing-Fang Li ${ }^{*}, \dagger$

${ }^{\dagger}$ Division of Analytical and Environmental Toxicology, Department of Laboratory Medicine and

Pathology, Faculty of Medicine and Dentistry, University of Alberta, Edmonton, Alberta T6G 2G3,

Canada

${ }^{\ddagger}$ Department of Chemistry, Faculty of Science, University of Alberta, Edmonton, Alberta, T6G 2G2, Canada

${ }^{*}$ To whom correspondence should be addressed:

E-mail: xingfang.li@ualberta.ca. Tel.: 1-780-492-5094 


\section{Table of Contents}

Scheme S1. Labeling reaction equation

Scheme S2. Methylation process of Tyr-Gln

Scheme S3. Product ion formation path of the precursor ions

Figure S1. Molar percentage of unreacted and monomethylated Tyr-Gln with increasing reaction time

Figure S2. Relationships between yield of dimethylated Tyr-Gln and reaction time

Figure S3. Recovery comparison of 5 dipeptides spiked in 1-L source water before and after labeling

Figure S4. TOF MS/MS spectra of tyrosine (Tyr) and 3 Tyr-containing peptides

Figure S5. Chromatogram and TOF MS spectrum of 1-minute window of a water sample

Figure S6. Manually screening the raw data via isotope patterns using AB Sciex OS software and Microsoft Excel software

Figure S7. LC-HRMS/MS analysis of isomers of isotopically labeled Ile and Leu

Figure S8. Extracted ion chromatograms of 8 dipeptides in unspiked and spiked source water

Table S1. MRM transition ions (Q1 and Q3 mass) and mass spectrometry parameters

Table S2. Comparison of retention time, intensity and signal-to-noise: unlabeled and labeled

Table S3. Retention time (RT), precursor ions and product ions of labeled standards

Table S4. Theoretical mass information of 20 amino acids, and their labeled precursor ions, and product ions

Table S5. Retention time (RT), precursor ions and product ions of isotopically labeled components identified in source water, and matching results of amino acids and polypeptides 


\section{Supplementary Schemes, Figures, and Tables}

$$
3 \mathrm{R}_{-} \mathrm{NH}_{2}+6 \mathrm{CH}_{2} \mathrm{O}+2 \mathrm{NaBH}_{3} \mathrm{CN} \rightarrow 3 \mathrm{R}-\mathrm{N}\left(\mathrm{CH}_{3}\right)_{2}+2 \mathrm{HCN}+2 \mathrm{NaH}_{2} \mathrm{BO}_{3}
$$

Scheme S1. Labeling reaction equation.

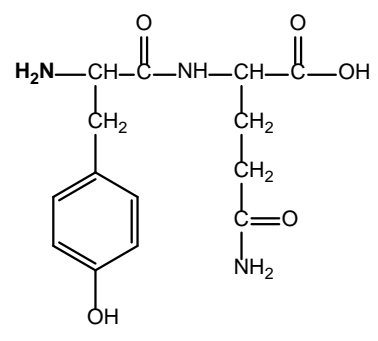

Tyr-GIn

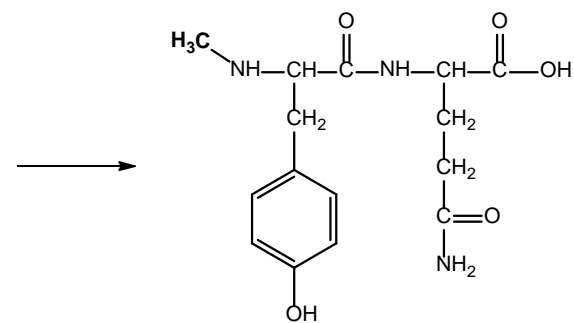

Monomethylated Tyr-GIn

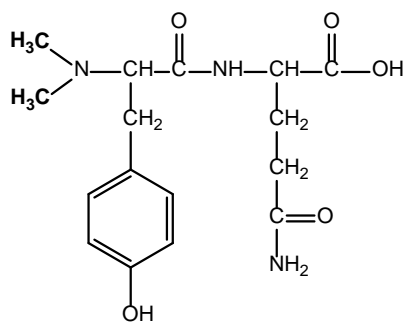

Dimethylated Tyr-GIn

Scheme S2. Methylation process of Tyr-Gln.

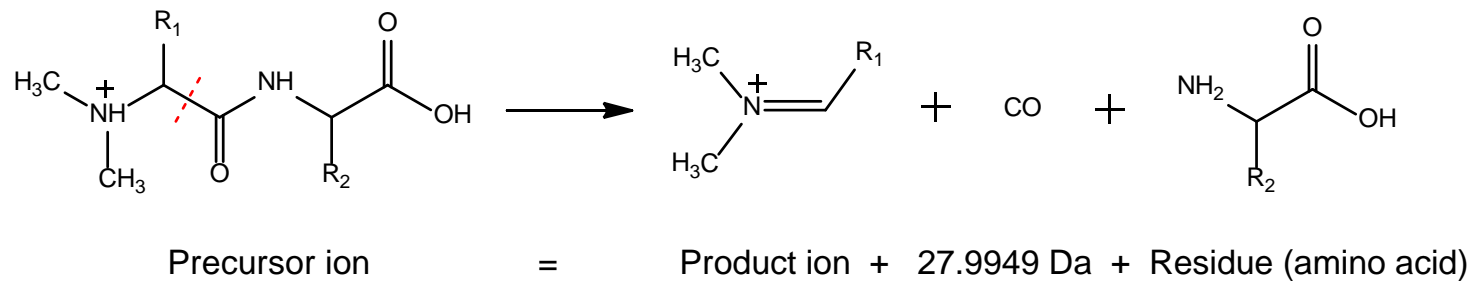

Scheme S3. Product ion formation path from the precursor ion. Neutral losses of CO and residue were suggested for calculation only, but are undetectable in MS/MS. 


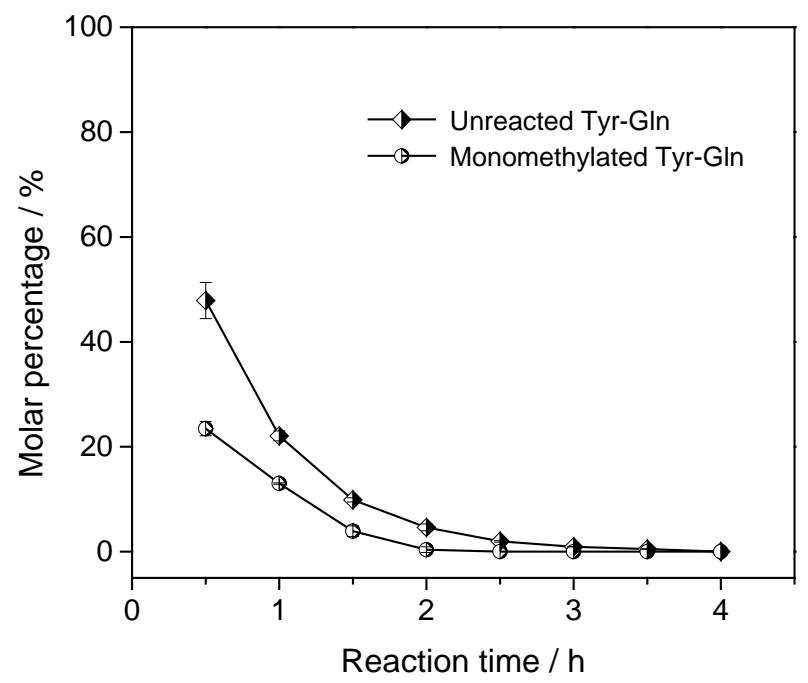

Figure S1. Molar percentage of unreacted and monomethylated Tyr-Gln with increasing reaction time. Starting concentration of Tyr-Gln was $5 \mu \mathrm{g} / \mathrm{L}(0.016 \mu \mathrm{mol} / \mathrm{L})$. During labeling reaction, we presumed that [unreacted] + [monomethylated $]+[$ dimethylated $]=0.016 \mu \mathrm{mol} / \mathrm{L}$. Concentrations of unreacted and dimethylated Tyr-Gln were determined by standard curves, and [monomethylated] = (0.016 - [unreacted] - [dimethylated]) $\mu \mathrm{mol} / \mathrm{L}$. Molar percentages were obtained using their concentrations divided by 0.016 .
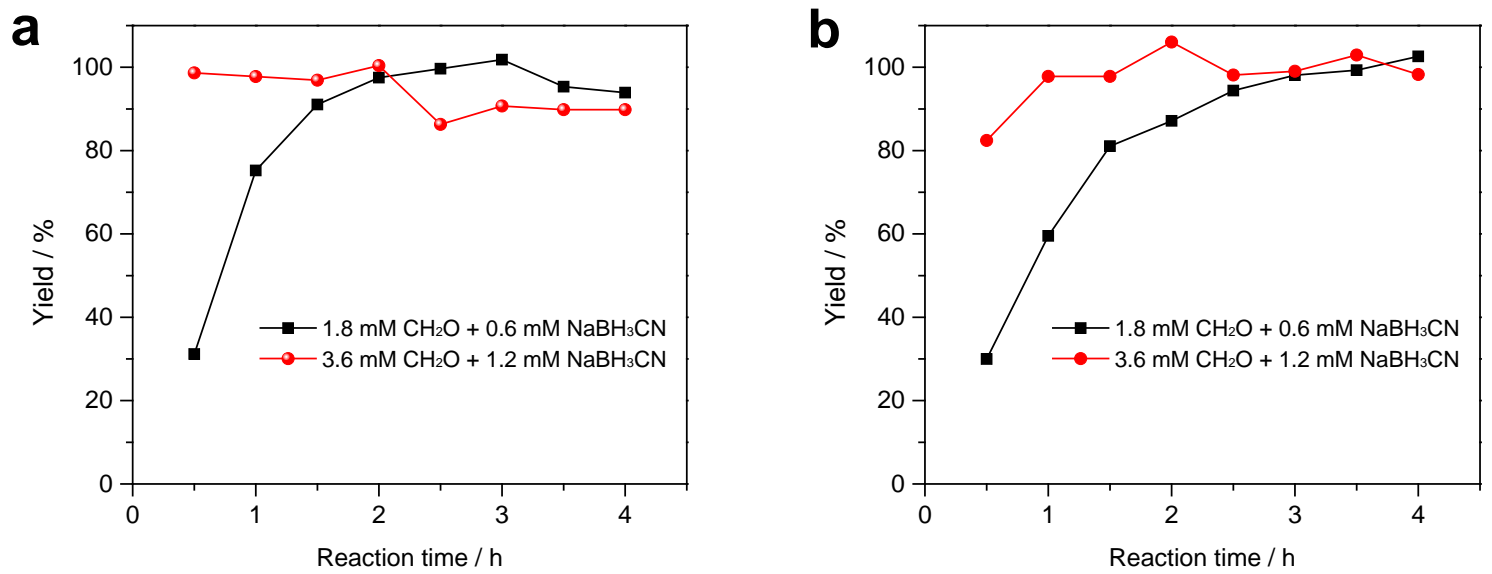

Figure S2. Relationships between yield of dimethylated Tyr-Gln and reaction time. Starting concentrations of Tyr-Gln were at (a) $100 \mathrm{ng} / \mathrm{L}$ and (b) $100 \mathrm{mg} / \mathrm{L}$. Note that labeling samples of Tyr-Gln at $100 \mathrm{mg} / \mathrm{L}$ were diluted 1,000,000 times before the analysis using LC-MS/MS (MRM). 


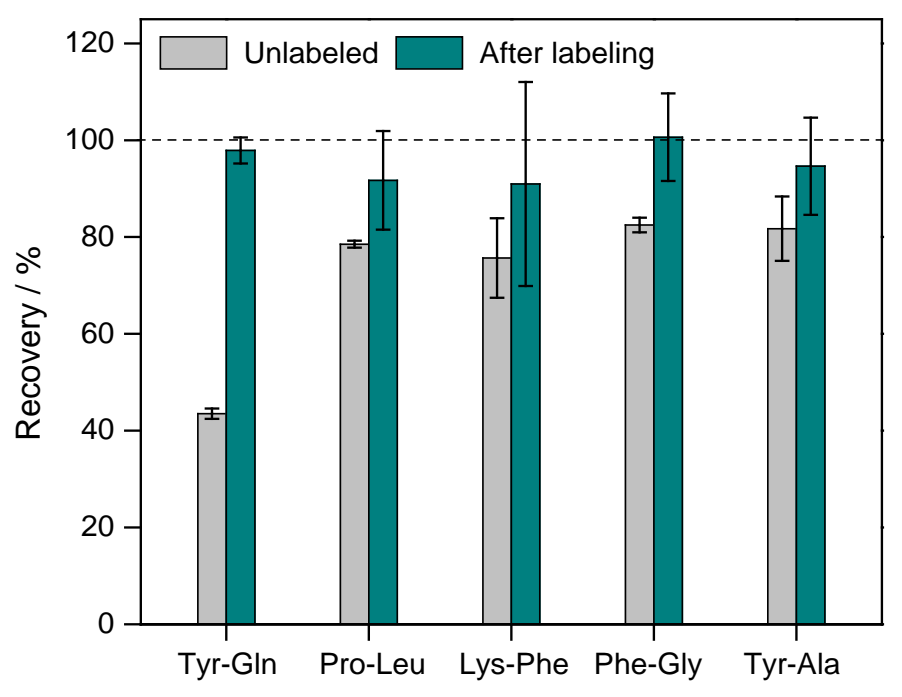

Figure S3. Recovery comparison of 5 dipeptides spiked in 1-L source water before and after labeling.

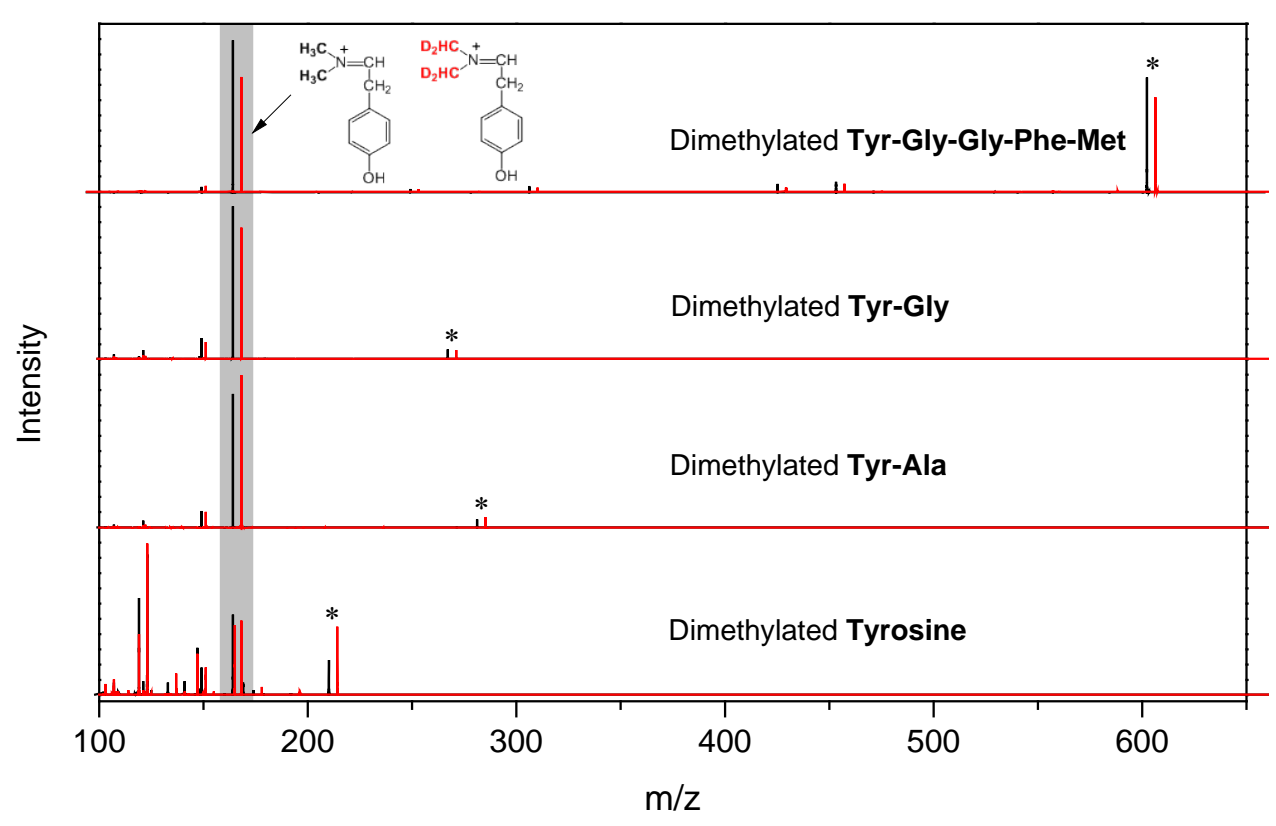

Figure S4. TOF MS/MS spectra of tyrosine (Tyr) and 3 Tyr-containing peptides. These 4 compounds showed the same product ion pairs of $\mathrm{m} / \mathrm{z}=164.1073 \mathrm{Da}$ (Light) and 168.1322 Da (Heavy), although they have different precursor ion pairs (marked with the symbol of '*'). 


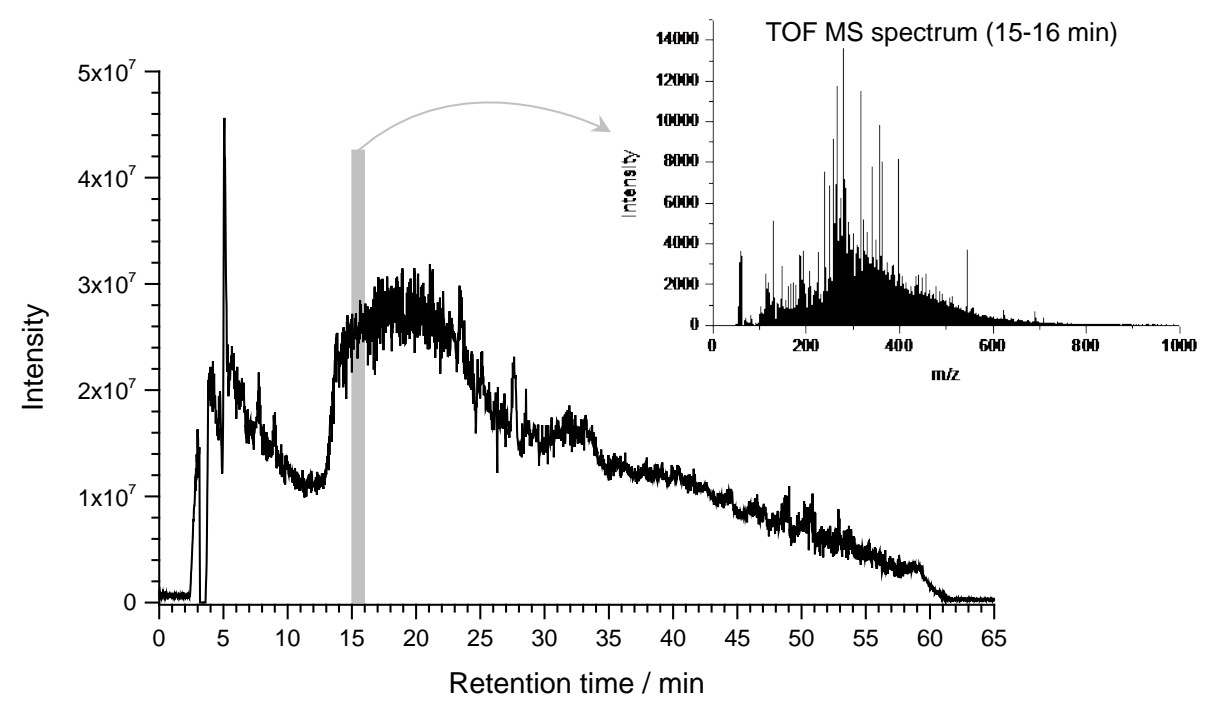

Figure S5. Chromatogram and TOF MS spectrum of 1-minute window of a water sample.

Workflow of Prioritization and Identification of Amino Contaminants in Source Water Using Isotope Patterns of Labeled Amines Description. As described in Figure 3, we followed this workflow to identify amino compounds in the massive LC-HRMS/MS data of a source water sample. The product ions of the prioritized components of $\Delta \mathrm{m}=2,4,6$, or $8 \mathrm{Da}$ are first matched with the theoretical product ions of the 20 amino acids (Table S4). When there is no match, the component is classified as an unknown amino compound. When matched with an amino acid, the compound with an N-terminal residue is identified as $\mathrm{AA}_{1}$. Next step is to identify the precursor ions. If a match occurs, it is identified as a free amino acid. If no match is observed, we then move on to calculate the $\mathrm{m} / \mathrm{z}$ of the C-terminal residue (Scheme S3) and match it with the exact mass of the unlabeled amino acids. If this calculated residue matches with an amino acid (marked as $\mathrm{AA}_{2}$ ), then we can tentatively identify the component as a dipeptide of $\mathrm{AA}_{1}-\mathrm{AA}_{2}$. If no match occurred, we tentatively identify it as an $\mathrm{AA}_{1}$-containing polypeptide comprised of $\geq 3$ amino acids residues. Thus, we have grouped the identified components into four separate categories: free amino acids, dipeptides, other polypeptides, and other unknown amino compounds. 
Figure S6. Manually screening the raw data via isotope patterns using AB Sciex OS software and Microsoft Excel software, detailed in the following screenshots (1) to (9).

(1) After converting source data of LC-HRMS/MS to a text file using AB Sciex OS software with an 'Analytics' tool, information of retention time, and precursor ion was picked out to a Microsoft Excel file.

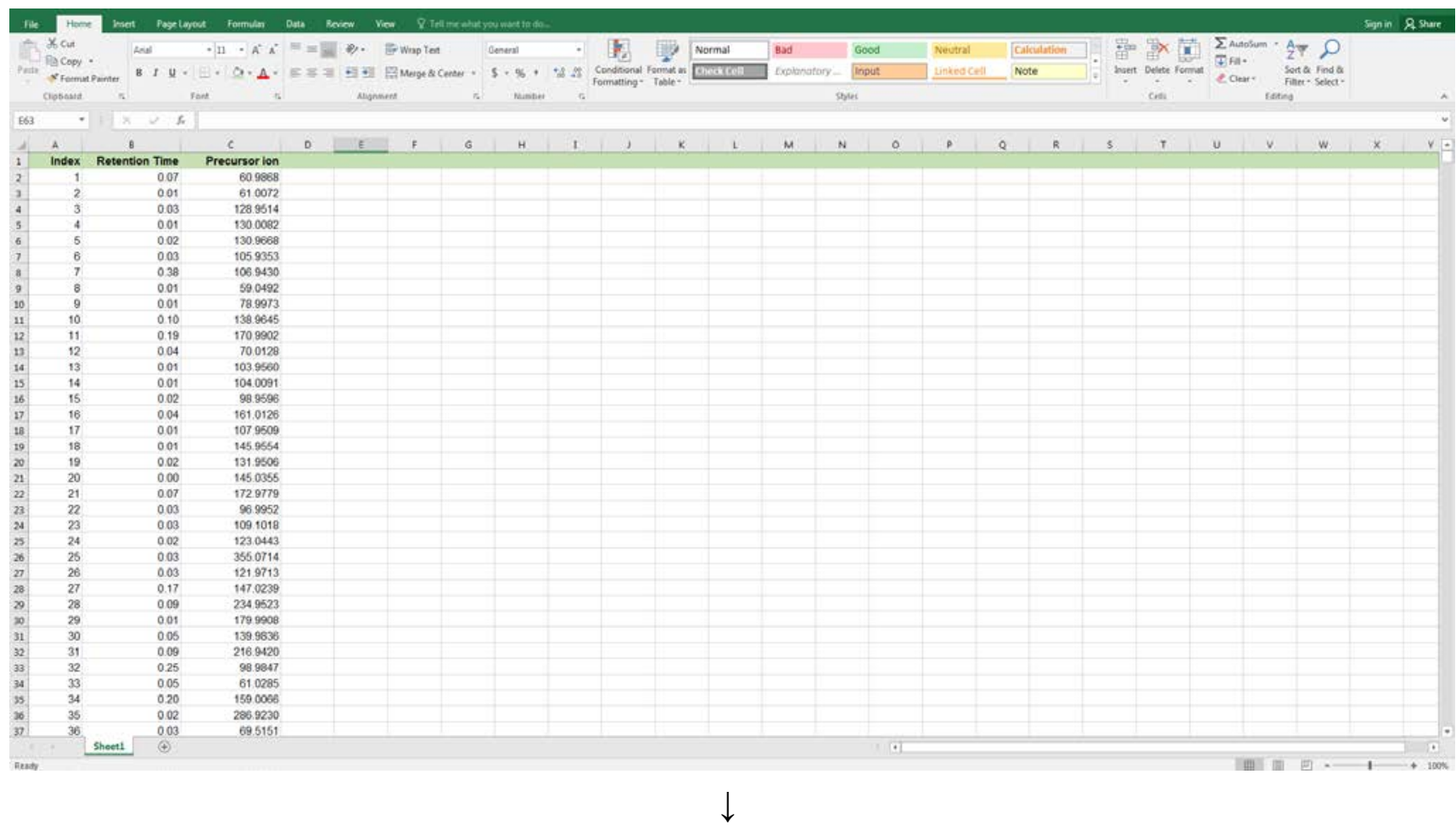

(2) Copy Column C (precursor ion) to Column D, E, F, G, and H. Two adjacent columns have one-row dislocation.

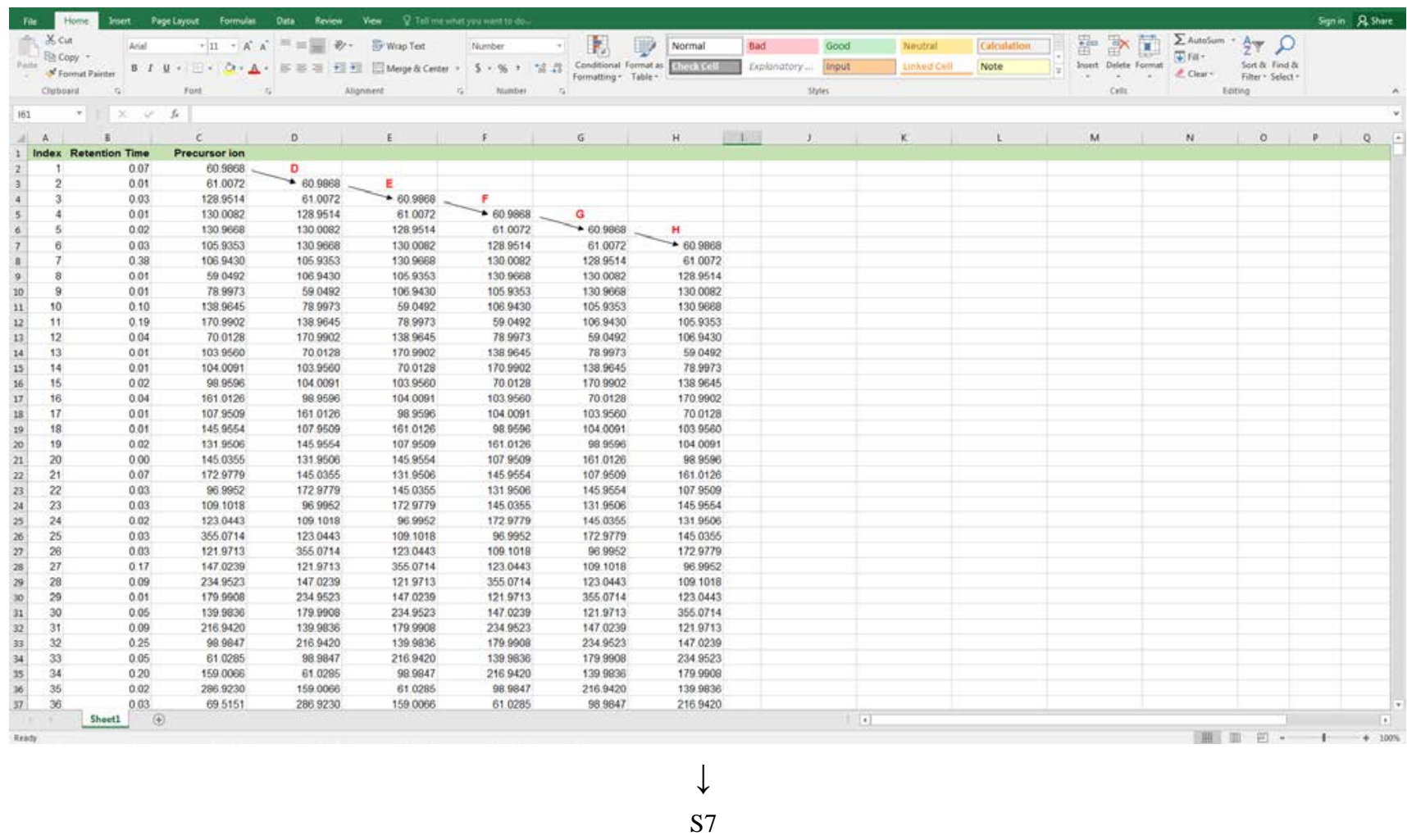


(3) Calculate difference between Column C and Column D-H using ABS function (output absolute value). ABS(C-D) represents difference between one number in Column $\mathbf{C}$ and the first one before it. ABS(C-E): the second one before it, and so on.

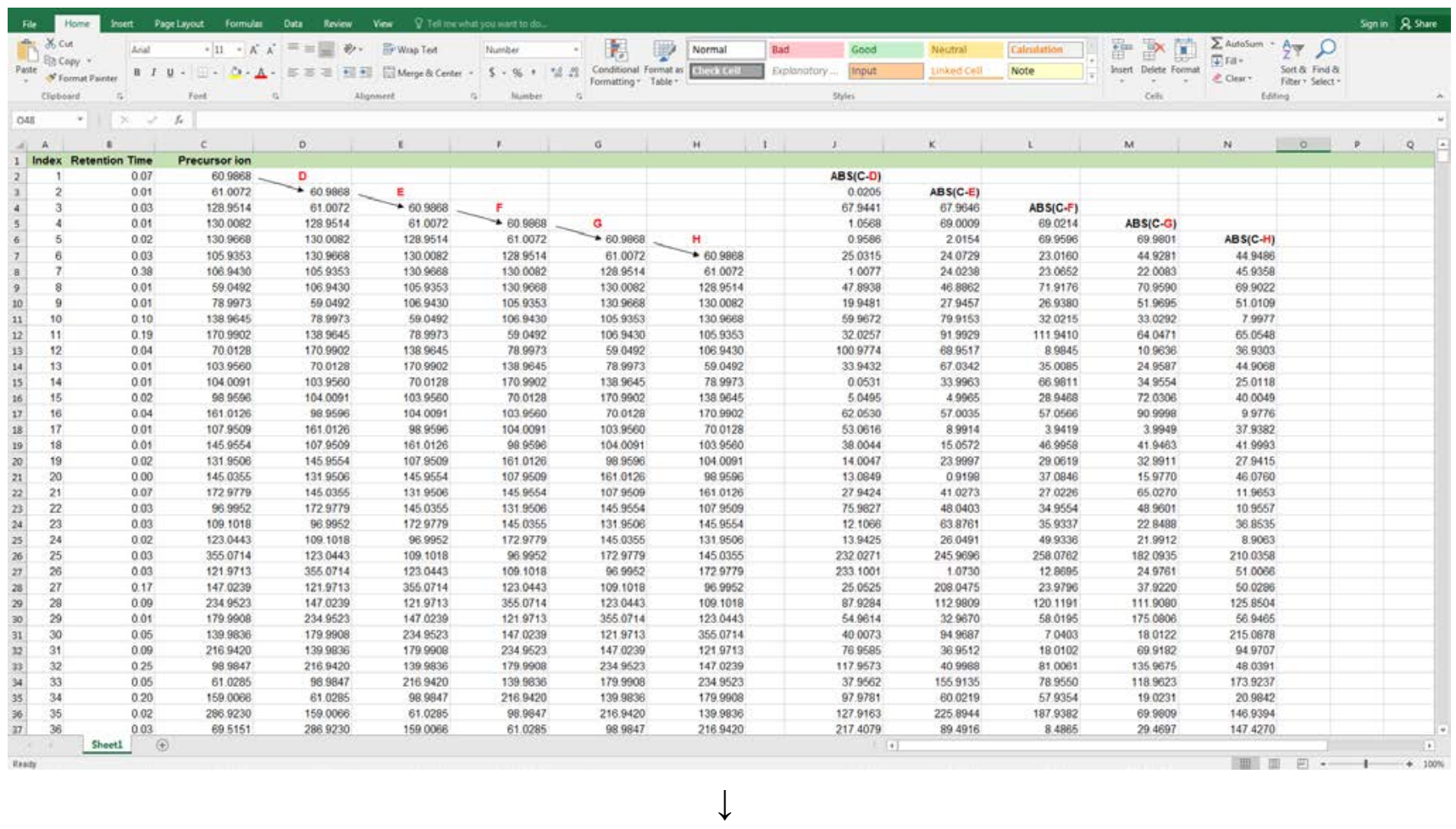

(4) Use the tool of 'Filter' to pick out the value between a given range, e.g., 4.024-4.026.

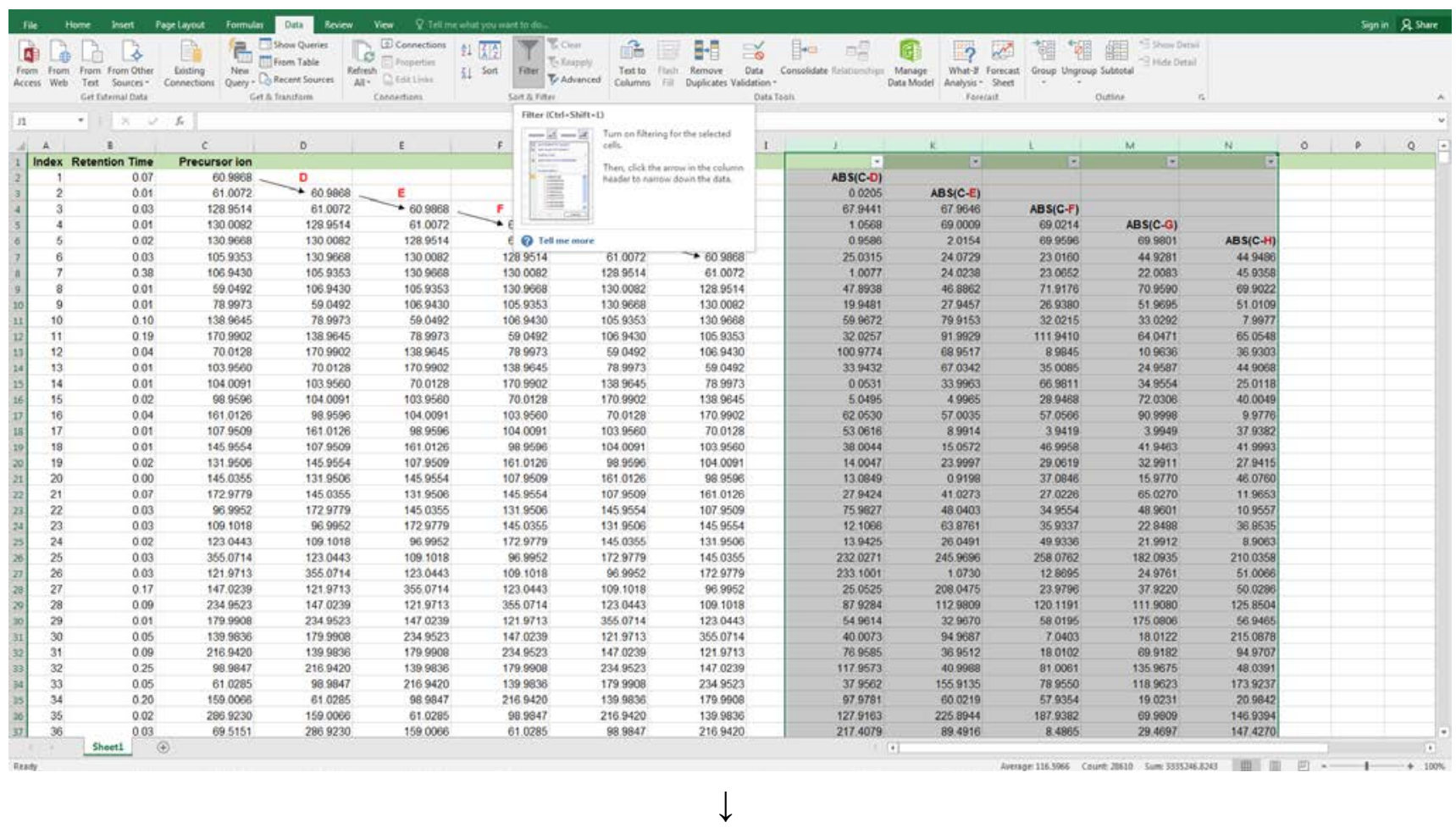


(5) Filter condition was set at 4.024-4.026.

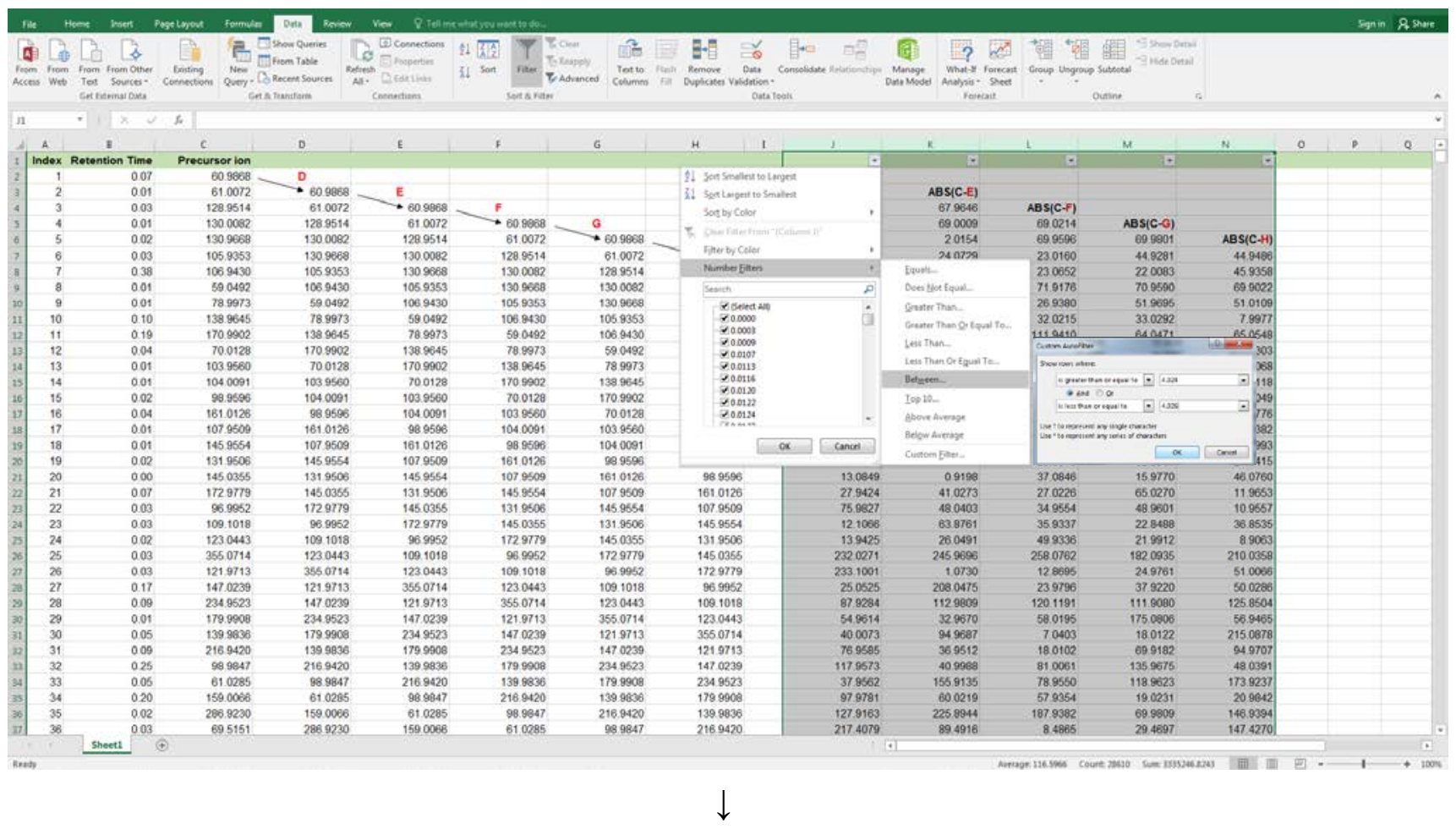

(6) The numbers ranging from 4.024 to 4.026 in Column $\mathbf{J}$ were screened out, and marked with color.

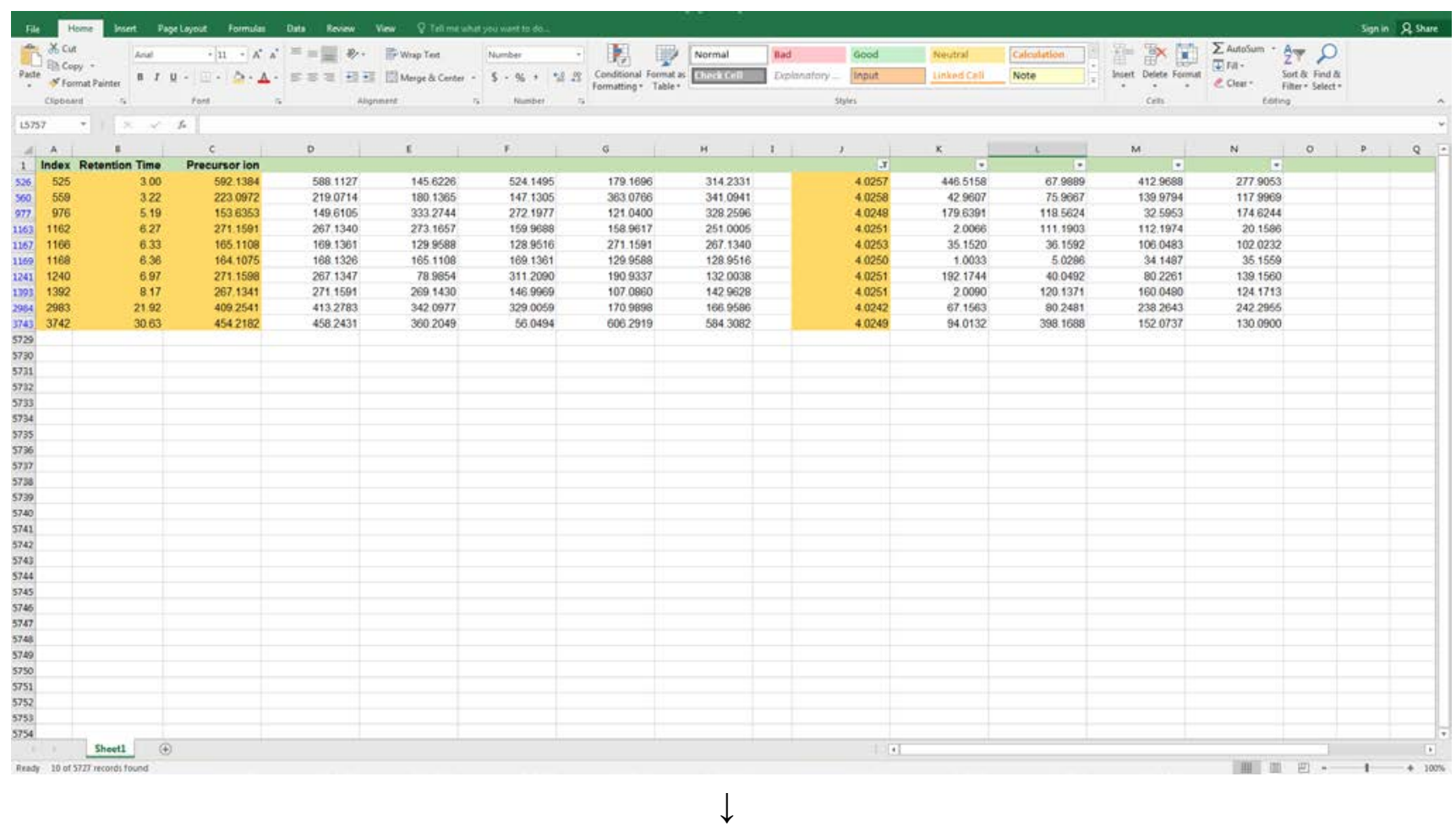


(7) Select All to return the window, as shown in Step (4). Repeat steps (5-7) to screen Columns K-N.

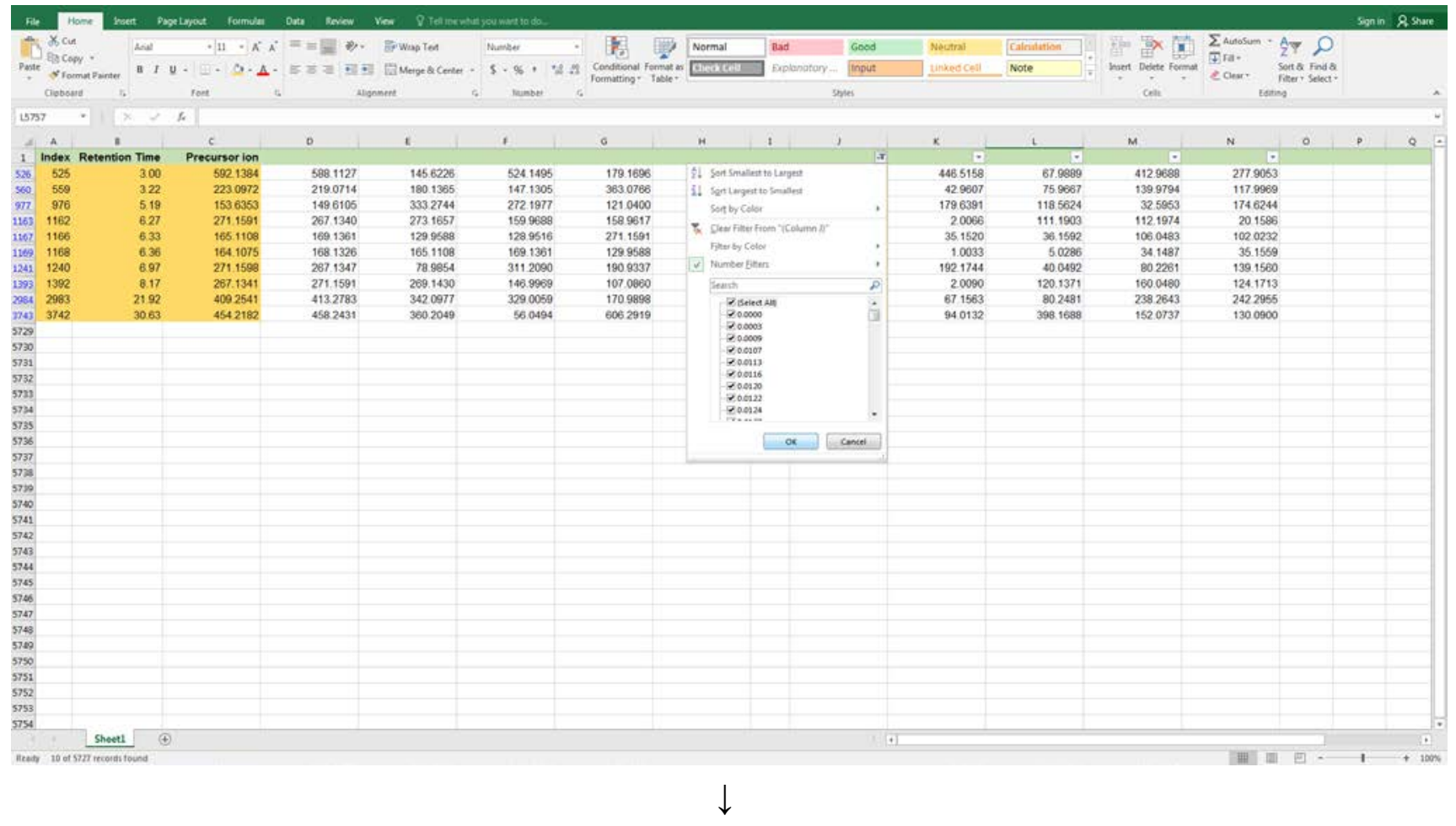

(8) If the marked difference was in Column $\mathbf{J}$, we checked the number in the same row in Column $\mathbf{C}$, and the first number before it. If the marked difference was in Column $\mathbf{N}$, we checked the fifth number before a given number in Column C. Finally, we achieved precursor ion pairs in Column $\mathbf{C}$.

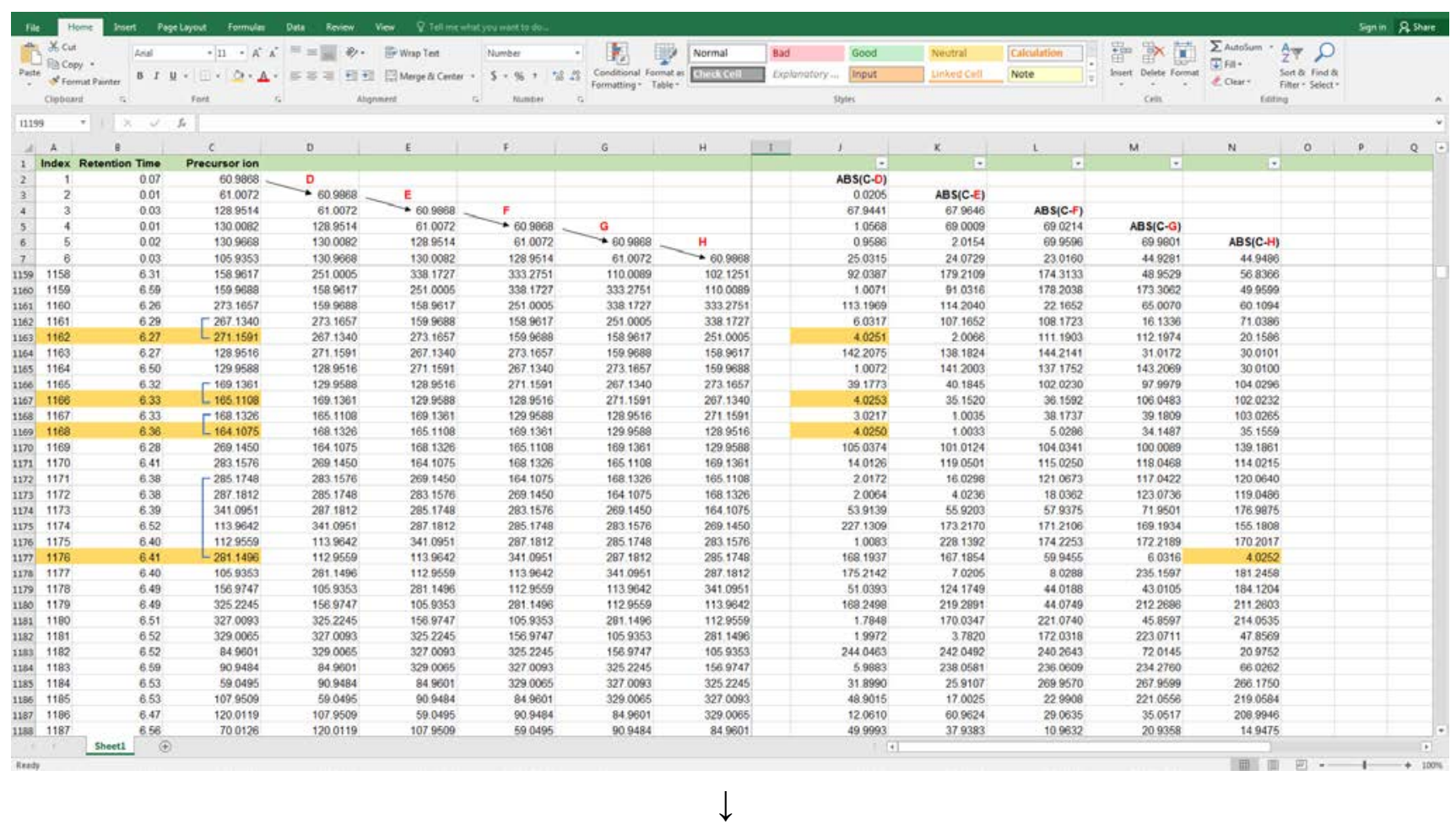


(9) Because abovementioned prioritized components were only acquired through the analysis of the precursor ion pairs, manual inspection of retention time and product ions on AB Sciex OS software is essential to validate the prioritized components. We set criteria that must show: (1) a pair of prioritized components show the same, or very close, retention time; (2) isotope patterns are detected in both MS (precursor ions) and MS/MS (product ions) spectra.

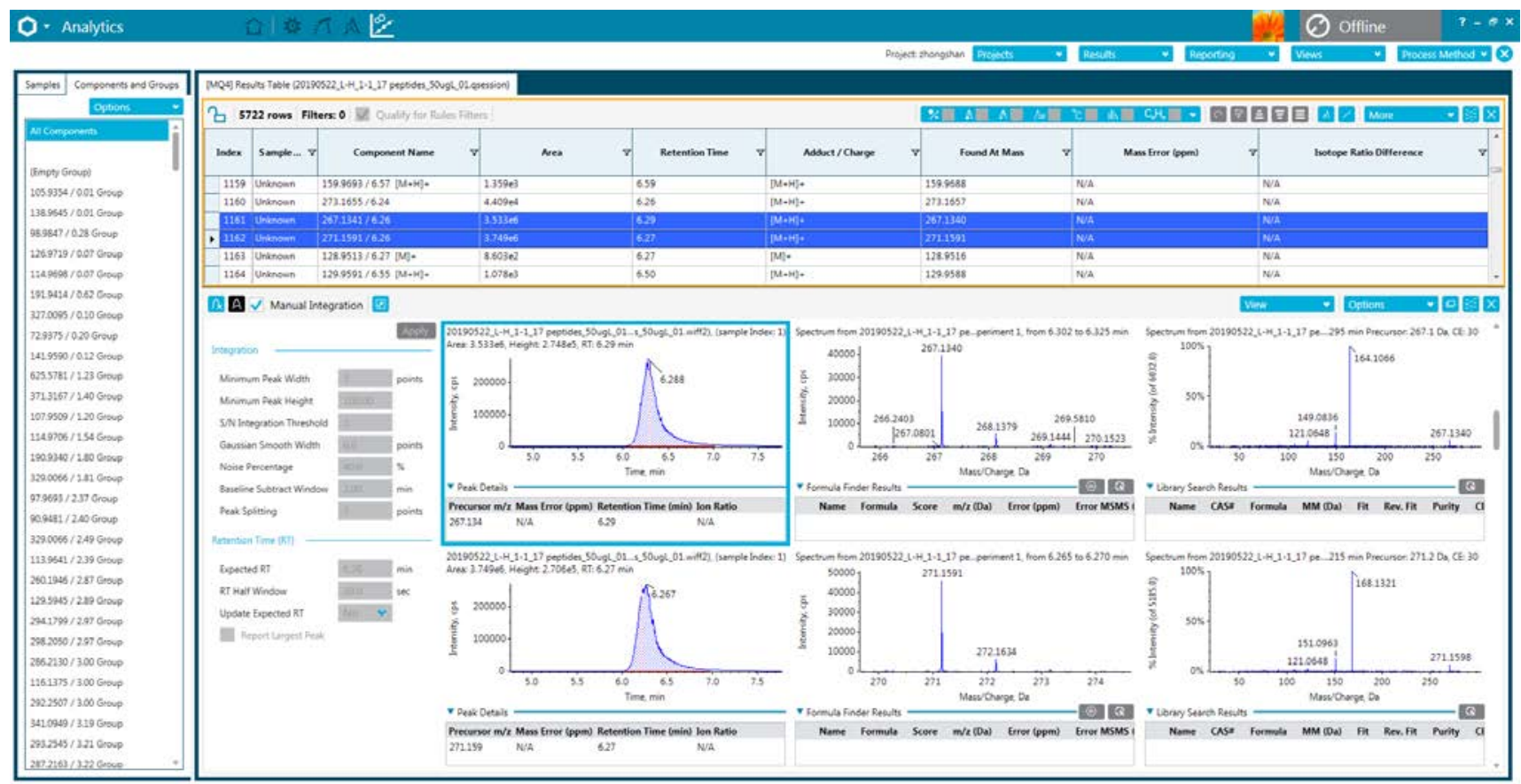


a

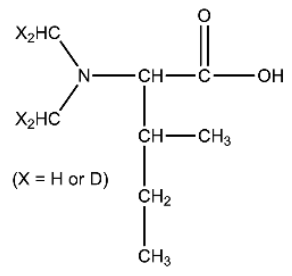

Dimethylated Ile

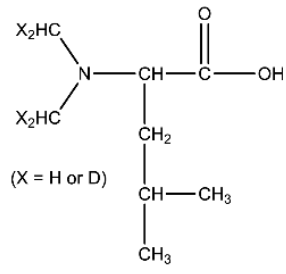

Dimethylated Leu

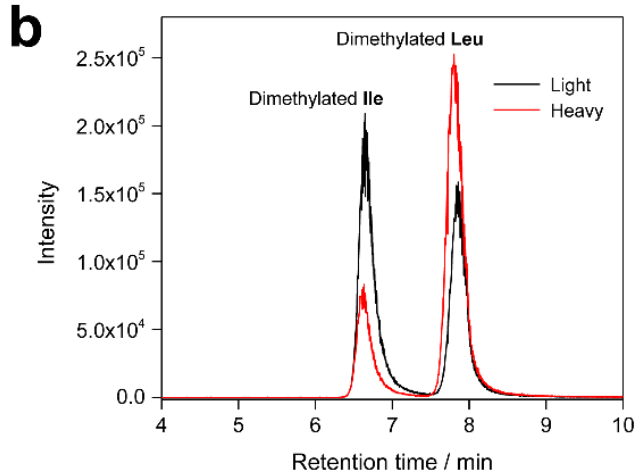

C

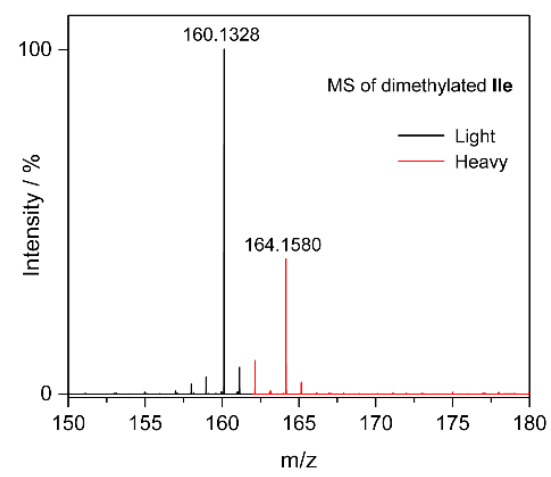

$\mathbf{e}$

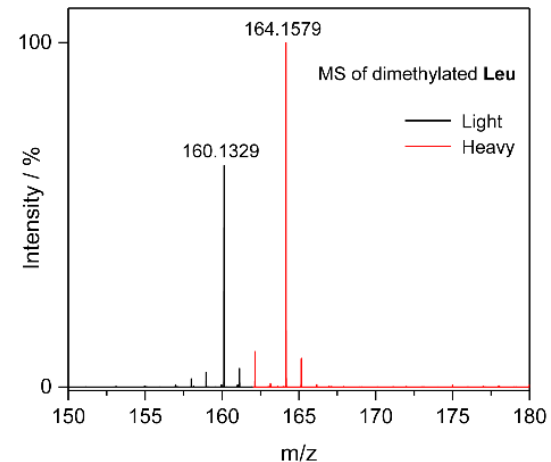

d

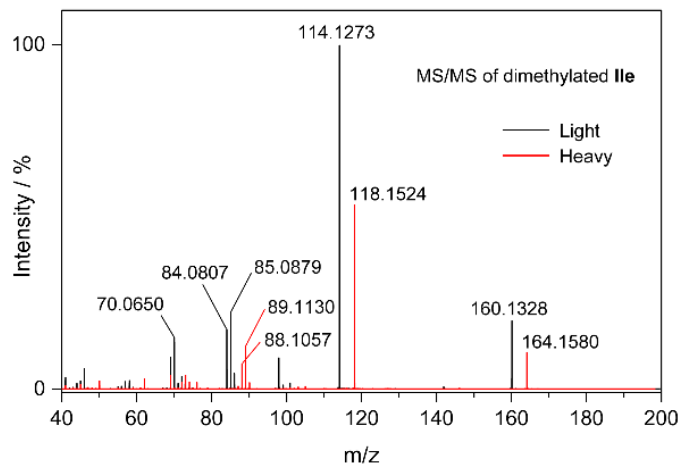

f

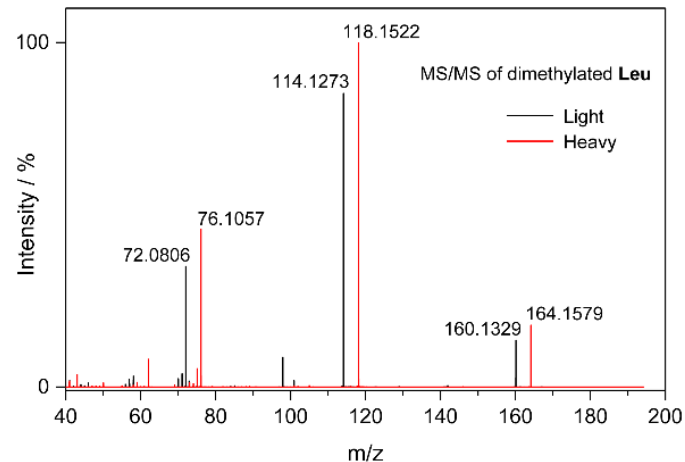

Figure S7. (a) Isomers of isotopically labeled Ile and Leu, (b) Extracted ion chromatograms, (c) TOF MS spectra, and (d) MS/MS spectra of dimethylated Ile. (e) TOF MS spectra, and (f) MS/MS spectra of dimethylated Leu.

Experimental method: a solution of Ile $(200 \mu \mathrm{g} / \mathrm{L})$ and Leu $(100 \mu \mathrm{g} / \mathrm{L})$ was labeled with $\mathrm{CH}_{2} \mathrm{O}$ (Light); another solution of Ile $(100 \mu \mathrm{g} / \mathrm{L})$ and Leu $(200 \mu \mathrm{g} / \mathrm{L})$ was labeled with $\mathrm{CD}_{2} \mathrm{O}$ (Heavy). These two solutions were then mixed at a volume ratio of 1:1, and analyzed using LC-HRMS/MS (IDA). Final ratios of light to heavy labeled product in the mixture were about 2:1 for dimethylated Ile, and 1:2 for dimethylated Leu. 

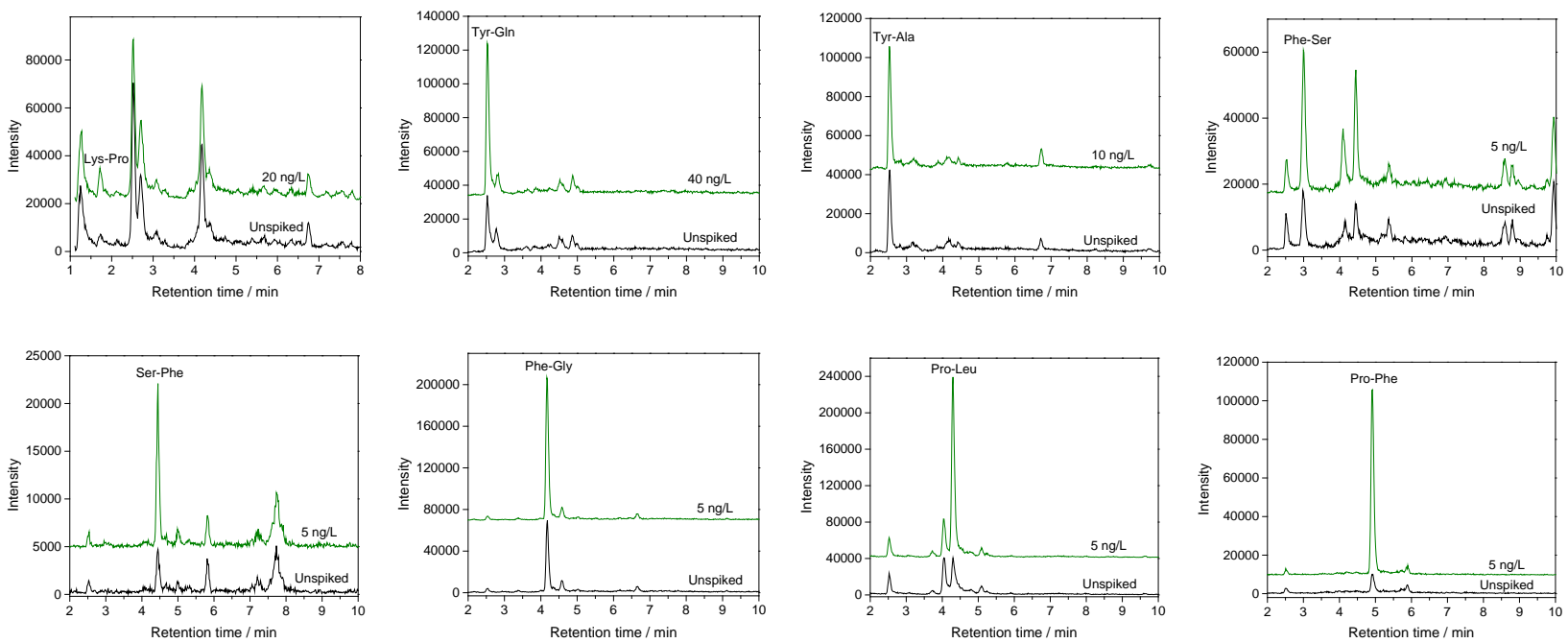

Figure S8. Extracted ion chromatograms of 8 dipeptides in unspiked and spiked source water after 100-fold preconcentration using MCX cartridges.

Experimental method: Five equal parts of source water (each $100 \mathrm{~mL}$, containing $200 \mu \mathrm{L}$ formic acid) were spiked with 8 dipeptides with concentration of 0,5, 10, 20, and $40 \mathrm{ng} / \mathrm{L}$. After SPE, the extracts (1 mL) were analyzed using LC-MS/MS (MRM). 
Table S1. MRM transition ions (Q1 and Q3 mass) and mass spectrometry parameters: declustering potential (DP), collision energy (CE), and collision cell exit potential (CXP).

\begin{tabular}{|c|c|c|c|c|c|}
\hline & $\mathrm{Q} 1(\mathrm{~m} / \mathrm{z})$ & $\mathrm{Q} 3(\mathrm{~m} / \mathrm{z})$ & $\mathrm{DP}(\mathrm{V})$ & CE (V) & $\mathrm{CXP}(\mathrm{V})$ \\
\hline \multirow[t]{2}{*}{ Tyr-Gln } & 310.1 & 136.1 & 55.3 & 29.0 & 14.5 \\
\hline & 310.1 & 147.0 & 41.3 & 20.5 & 13.0 \\
\hline \multirow[t]{2}{*}{$\mathrm{CH}_{3}$-Tyr-Gln } & 324.1 & 123.1 & 44.6 & 24.3 & 15.4 \\
\hline & 324.1 & 150.1 & 51.4 & 28.4 & 14.6 \\
\hline \multirow{2}{*}{$\left(\mathrm{CH}_{3}\right)_{2}$-Tyr-Gln } & 338.2 & 164.1 & 59.7 & 27.7 & 14.9 \\
\hline & 338.2 & 217.9 & 45.1 & 15.2 & 17.3 \\
\hline \multirow[t]{2}{*}{ Phe-Gly } & 223.1 & 120.1 & 71.8 & 22.4 & 10.17 \\
\hline & 223.1 & 91.1 & 71.8 & 61.0 & 8.0 \\
\hline \multirow[t]{2}{*}{$\left(\mathrm{CH}_{3}\right)_{2}$-Phe-Gly } & 251.2 & 148.1 & 56.5 & 23.1 & 16.8 \\
\hline & 251.2 & 132.9 & 55.5 & 46.7 & 13.7 \\
\hline \multirow[t]{2}{*}{ Tyr-Ala } & 253.2 & 135.7 & 75.0 & 24.0 & 18.0 \\
\hline & 253.2 & 119.1 & 75.0 & 36.0 & 18.0 \\
\hline \multirow[t]{2}{*}{$\left(\mathrm{CH}_{3}\right)_{2}$-Tyr-Ala } & 281.2 & 164.0 & 58.2 & 24.0 & 14.8 \\
\hline & 281.2 & 149.0 & 58.9 & 46.7 & 14.5 \\
\hline \multirow[t]{2}{*}{ Pro-Leu } & 229.1 & 70.0 & 48.4 & 21.3 & 8.6 \\
\hline & 229.1 & 99.0 & 108.4 & 26.9 & 9.8 \\
\hline \multirow[t]{2}{*}{$\mathrm{CH}_{3}$-Pro-Leu } & 243.2 & 84.0 & 61.7 & 25.2 & 10.0 \\
\hline & 243.2 & 99.0 & 133.6 & 30.6 & 10.1 \\
\hline \multirow[t]{2}{*}{ Lys-Phe } & 294.2 & 84.1 & 107.0 & 36.0 & 7.2 \\
\hline & 294.2 & 129.0 & 116.0 & 19.6 & 12.3 \\
\hline \multirow[t]{2}{*}{$\left(\mathrm{CH}_{3}\right)_{4}$-Lys-Phe } & 350.2 & 157.1 & 148.2 & 27.3 & 14.2 \\
\hline & 350.2 & 114.0 & 146.1 & 40.8 & 12.1 \\
\hline \multirow[t]{2}{*}{ Lys-Pro } & 244.2 & 84.0 & 36.1 & 33.0 & 11.0 \\
\hline & 244.2 & 116.0 & 68.7 & 24.9 & 8.0 \\
\hline \multirow[t]{2}{*}{ Pro-Phe } & 263.1 & 70.0 & 34.8 & 23.3 & 7.1 \\
\hline & 263.1 & 120.0 & 28.9 & 31.9 & 10.3 \\
\hline \multirow[t]{2}{*}{ Phe-Ser } & 253.1 & 120.0 & 46.9 & 32.9 & 13.1 \\
\hline & 253.1 & 102.9 & 49.7 & 54.0 & 11.0 \\
\hline \multirow[t]{2}{*}{ Ser-Phe } & 253.1 & 60.0 & 32.0 & 39.4 & 7.3 \\
\hline & 253.1 & 166.1 & 29.4 & 18.9 & 19.2 \\
\hline
\end{tabular}

$\left(\mathrm{CH}_{3}\right)_{n}-\mathrm{AA}_{1}-\mathrm{AA}_{2}$ represents labeled products with monomethylation $(n=1)$, dimethylation $(n=2)$, tetramethylation $(n=4)$. MRM transition ions and mass spectrometry parameters were optimized on an AB Sciex QTRAP 5500 mass spectrometer. 
Table S2. Comparison of retention time, intensity and signal-to-noise: unlabeled and labeled.

\begin{tabular}{|c|c|c|c|c|c|c|c|c|}
\hline & \multirow[b]{2}{*}{ Peptides } & \multirow[b]{2}{*}{ Methylation $^{a}$} & \multicolumn{2}{|c|}{ Retention time / min } & \multicolumn{2}{|c|}{ Intensity } & \multicolumn{2}{|c|}{ Signal-to-Noise } \\
\hline & & & Unlabeled & Labeled & Unlabeled & Labeled & Unlabeled & Labeled \\
\hline 1 & Gly-Ala & Di- & 3.0 & 3.2 & 3817 & 28500 & 271 & 1552 \\
\hline 2 & Tyr-Gln & Di- & 5.0 & 5.1 & 58333 & 55167 & 7014 & 9452 \\
\hline 3 & Tyr-Gly & Di- & 5.0 & 5.9 & 26000 & 60667 & 1846 & 4720 \\
\hline 4 & Tyr-Ala & Di- & 5.0 & 6.2 & 34333 & 84667 & 5874 & 5462 \\
\hline 5 & Gly-Tyr & Di- & 5.7 & 7.7 & 8733 & 23367 & 778 & 1620 \\
\hline 6 & Lys-Phe & Tetra- & 7.6 & 14.2 & 2417 & 6133 & 638 & 2138 \\
\hline 7 & Phe-Gly & Di- & 8.7 & 13.5 & 10767 & 36333 & 1112 & 5349 \\
\hline 8 & Pro-Leu & Mono- & 9.7 & 13.1 & 37833 & 65333 & 4521 & 17104 \\
\hline 9 & Val-Tyr-Val & Di- & 16.5 & 18.2 & 55000 & 97667 & 8276 & 18673 \\
\hline 10 & Tyr-Gly-Gly-Phe-Met & Di- & 21.5 & 22.1 & 23167 & 24533 & 147205 & 159492 \\
\hline
\end{tabular}

${ }^{a}$ Mono-, Di-, Tetra-, represent that one, two, and four methyl groups were introduced to peptides. Experimental method: Two equal parts of standard solution (each $100 \mu \mathrm{g} / \mathrm{L}$, except Lys-Phe at $500 \mu \mathrm{g} / \mathrm{L}$ in Optima water). One of solutions was labeled with $\mathrm{CH}_{2} \mathrm{O}(3.6 \mathrm{mM})$. Then these two solutions were analyzed using LC-HRMS/MS (IDA) method. 
Table S3. Retention time (RT), precursor ions and product ions of labeled standards.

\begin{tabular}{|c|c|c|c|c|c|c|}
\hline Standards $^{a}$ & Labeling & $\mathrm{RT} / \mathrm{min}$ & Precursor ions & $\Delta \mathrm{m} / \mathrm{z}^{b}$ & Product ions & $\Delta \mathrm{m} / \mathrm{z}^{b}$ \\
\hline \multirow[t]{2}{*}{ Pro-Leu } & Light & 13.2 & 243.1702 & 2.0125 & 84.0810 & 2.0124 \\
\hline & Heavy & 13.2 & 245.1827 & & 86.0934 & \\
\hline \multirow[t]{2}{*}{ Pro-Lys } & Light & 3.1 & 286.2131 & 6.0380 & 84.0808 & 2.0122 \\
\hline & Heavy & 3.1 & 292.2511 & & 86.0930 & \\
\hline \multirow[t]{2}{*}{ Lys-Phe } & Light & 9.7 & 350.2447 & 8.0502 & 157.1702 & 8.0504 \\
\hline & Heavy & 9.7 & 358.2949 & & 165.2206 & \\
\hline \multirow[t]{2}{*}{ Gly-Ala } & Light & 3.3 & 175.1080 & 4.0250 & 58.0652 & 4.0252 \\
\hline & Heavy & 3.3 & 179.1330 & & 62.0904 & \\
\hline \multirow[t]{2}{*}{ Gly-Tyr } & Light & 7.3 & 267.1347 & 4.0251 & 58.0656 & 4.0248 \\
\hline & Heavy & 7.4 & 271.1598 & & 62.0904 & \\
\hline \multirow[t]{2}{*}{ Tyrosine } & Light & 6.6 & 210.1127 & 4.0252 & 164.1072 & 4.0250 \\
\hline & Heavy & 6.5 & 214.1379 & & 168.1322 & \\
\hline \multirow[t]{2}{*}{ Tyr-Gln } & Light & 5.1 & 338.1710 & 4.0252 & 164.1073 & 4.0253 \\
\hline & Heavy & 5.1 & 342.1962 & & 168.1326 & \\
\hline \multirow[t]{2}{*}{ Tyr-Ala } & Light & 5.9 & 281.1498 & 4.0250 & 164.1075 & 4.0247 \\
\hline & Heavy & 5.9 & 285.1748 & & 168.1322 & \\
\hline \multirow[t]{2}{*}{ Tyr-Gly } & Light & 5.8 & 267.1341 & 4.0250 & 164.1073 & 4.0248 \\
\hline & Heavy & 5.8 & 271.1591 & & 168.1321 & \\
\hline \multirow[t]{2}{*}{ Val-Tyr-Val } & Light & 18.64 & 408.2497 & 4.0247 & 100.1123 & 4.0251 \\
\hline & Heavy & 18.63 & 412.2744 & & 104.1374 & \\
\hline \multirow{2}{*}{ Tyr-Gly-Gly-Phe-Met } & Light & 22.9 & 602.2659 & 4.0254 & 164.1073 & 4.0251 \\
\hline & Heavy & 22.9 & 606.2913 & & 168.1324 & \\
\hline
\end{tabular}

${ }^{a} 50 \mu \mathrm{g} / \mathrm{L} .{ }^{b} z=1$. 
Table S4. Theoretical mass information of 20 amino acids, and their labeled precursor ions, and product ions.

\begin{tabular}{|c|c|c|c|c|c|c|}
\hline \multirow[b]{2}{*}{ Amino acid } & & Unlabeled & $\begin{array}{l}\text { Light labeled } \\
\text { precursor ions } \\
\end{array}$ & $\begin{array}{l}\text { Light labeled } \\
\text { product ions }\end{array}$ & $\begin{array}{l}\text { Heavy labeled } \\
\text { product ions }\end{array}$ & \multirow[b]{2}{*}{-R (side chain) } \\
\hline & & & & ${ }_{\mathrm{H}_{3}}^{{ }_{3}^{3} \mathrm{C}} \mathrm{C}^{\mathrm{N}} \mathrm{C}^{+}=$ & $\mathrm{D}_{2} \mathrm{HC}^{\mathrm{N}} \mathrm{N}^{\mathrm{N}}={ }_{\mathrm{N}}^{+}=\mathrm{CH}$ & \\
\hline Glycine & Gly & 75.0320 & 104.0712 & 58.0657 & 62.0908 & $-\mathrm{H}$ \\
\hline Alanine & Ala & 89.0477 & 118.0868 & 72.0813 & 76.1064 & $-\mathrm{CH}_{3}$ \\
\hline Proline & Pro & 115.0633 & 130.0868 & 84.0813 & 86.0939 & $-\mathrm{CH}_{2} \mathrm{CH}_{2} \mathrm{CH}_{2-}$ \\
\hline Serine & Ser & 105.0426 & 134.0817 & 88.0762 & 92.1013 & $-\mathrm{CH}_{2}-\mathrm{OH}$ \\
\hline Valine & Val & 117.0790 & 146.1181 & 100.1126 & 104.1377 & $-\mathrm{CH}\left(\mathrm{CH}_{3}\right)_{2}$ \\
\hline Threonine & Thr & 119.0582 & 148.0974 & 102.0919 & 106.1170 & $-\mathrm{CH}\left(\mathrm{CH}_{3}\right)-\mathrm{OH}$ \\
\hline Cysteine & Cys & 121.0197 & 150.0589 & 104.0534 & 108.0785 & $-\mathrm{CH}_{2}-\mathrm{SH}$ \\
\hline Isoleucine & Ile & 131.0946 & 160.1338 & 114.1283 & 118.1534 & $-\mathrm{CH}\left(\mathrm{CH}_{3}\right)-\mathrm{CH}_{2} \mathrm{CH}_{3}$ \\
\hline Leucine & Leu & 131.0946 & 160.1338 & 114.1283 & 118.1534 & $-\mathrm{CH}_{2}-\mathrm{CH}\left(\mathrm{CH}_{3}\right)_{2}$ \\
\hline Asparagine & Asn & 132.0535 & 161.0926 & 115.0871 & 119.1122 & $-\mathrm{CH}_{2}-\mathrm{CONH}_{2}$ \\
\hline Aspartic acid & Asp & 133.0375 & 162.0766 & 116.0712 & 120.0963 & $-\mathrm{CH}_{2}-\mathrm{COOH}$ \\
\hline Glutamine & Gln & 146.0691 & 175.1083 & 129.1028 & 133.1279 & $-\mathrm{CH}_{2}-\mathrm{CH}_{2}-\mathrm{CONH}_{2}$ \\
\hline Glutamic acid & Glu & 147.0532 & 176.0923 & 130.0868 & 134.1119 & $-\mathrm{CH}_{2}-\mathrm{CH}_{2}-\mathrm{COOH}$ \\
\hline Methionine & Met & 149.0510 & 178.0902 & 132.0847 & 136.1098 & $-\mathrm{CH}_{2}-\mathrm{CH}_{2}-\mathrm{S}-\mathrm{CH}_{3}$ \\
\hline Histidine & His & 155.0695 & 184.1086 & 138.1031 & 142.1282 & $-\mathrm{CH}_{2}-\mathrm{C}_{3} \mathrm{~N}_{2} \mathrm{H}_{3}$ \\
\hline Phenylalanine & Phe & 165.0790 & 194.1181 & 148.1126 & 152.1377 & $-\mathrm{CH}_{2}-\mathrm{C}_{6} \mathrm{H}_{5}$ \\
\hline Arginine & Arg & 174.1117 & 203.1508 & 157.1453 & 161.1704 & $-\left(\mathrm{CH}_{2}\right)_{3}-\mathrm{NH}-\mathrm{C}(=\mathrm{NH})-\mathrm{NH}_{2}$ \\
\hline Lysine & Lys & 146.1055 & 203.1760 & 157.1705 & 165.2207 & $-\left(\mathrm{CH}_{2}\right)_{4}-\mathrm{NH}_{2}$ \\
\hline Tyrosine & Tyr & 181.0739 & 210.1130 & 164.1075 & 168.1326 & $-\mathrm{CH}_{2}-\mathrm{C}_{6} \mathrm{H}_{4}-\mathrm{OH}$ \\
\hline Tryptophan & Trp & 204.0899 & 233.1290 & 187.1235 & 191.1486 & $-\mathrm{CH}_{2}-\mathrm{C}_{8} \mathrm{NH}_{6}$ \\
\hline
\end{tabular}

Mass information of unlabeled amino acids was obtained using ChemDraw software with 'exact mass'. Protonated ion information was obtained using ChemDraw software with ' $\mathrm{m} / \mathrm{z}$ '. 
Table S5. Retention time (RT), precursor ions and product ions of isotopically labeled compounds identified from source water, and matching results of amino acids (AA) and polypeptides.

Part I. Amino acids (Identified number $=2$ )

\begin{tabular}{|c|c|c|c|c|c|c|c|c|c|c|}
\hline \multirow{2}{*}{ No. } & \multirow{2}{*}{$\begin{array}{l}\mathrm{RT} \\
\text { / } \mathrm{min}\end{array}$} & \multirow{2}{*}{$\begin{array}{l}\text { Precursor } \\
\text { ions }\end{array}$} & \multirow{2}{*}{$\begin{array}{c}\Delta \mathrm{m} / z \\
(z=1)\end{array}$} & \multirow{2}{*}{$\begin{array}{l}\text { Product ions } \\
\text { (i) }\end{array}$} & \multirow{2}{*}{$\begin{array}{l}\text { Product ions } \\
\text { (ii) }\end{array}$} & \multicolumn{2}{|c|}{ Match of product ion } & \multicolumn{3}{|c|}{ Match of amino compound } \\
\hline & & & & & & AA & Error/ $\mathrm{Da}^{a}$ & Compounds & {$[\mathrm{M}+\mathrm{H}]^{+b}$} & Error / $\mathrm{Da}^{\mathrm{c}}$ \\
\hline \multirow[t]{2}{*}{1} & 6.7 & 160.1327 & 4.0252 & 114.1270 & 85.0882 & Ile & 0.0013 & Ile & 160.1338 & 0.0011 \\
\hline & 6.6 & 164.1579 & & 118.1520 & 89.1133 & & & & & \\
\hline \multirow[t]{2}{*}{2} & 7.8 & 160.1326 & 4.0251 & 114.1266 & 72.0801 & Leu & 0.0017 & Leu & 160.1338 & 0.0012 \\
\hline & 7.8 & 164.1577 & & 118.1517 & 76.1053 & & & & & \\
\hline \multicolumn{11}{|c|}{ Part II. Dipeptides (Identified number = 56) } \\
\hline \multirow[t]{2}{*}{3} & 4.5 & 300.2283 & 8.0506 & 157.1698 & 203.1754 & Lys & 0.0007 & Lys-Pro & 300.2287 & 0.0006 \\
\hline & 4.5 & 308.2788 & & 165.2196 & 211.2263 & & & & & \\
\hline \multirow[t]{2}{*}{4} & 5.7 & 243.1704 & 4.0252 & 100.1116 & 85.0882 & Val & 0.0010 & Val-Pro & 243.1709 & 0.0005 \\
\hline & 5.7 & 247.1956 & & 104.1366 & 89.1128 & & & & & \\
\hline \multirow[t]{2}{*}{5} & 5.9 & 338.1711 & 4.0249 & 164.1072 & & Tyr & 0.0003 & Tyr-Gln & 338.1716 & 0.0005 \\
\hline & 5.9 & 342.196 & & 168.1322 & & & & & & \\
\hline \multirow[t]{2}{*}{6} & 6.3 & 275.1604 & 4.0251 & 114.1271 & 84.0805 & Ile & 0.0012 & Ile-Asp & 275.1607 & 0.0003 \\
\hline & 6.3 & 279.1855 & & 118.1524 & 88.1506 & & & & & \\
\hline \multirow[t]{2}{*}{7} & 6.4 & 289.1764 & 4.0246 & 114.1272 & 85.0882 & Ile & 0.0011 & Ile-Glu & 289.17630 & -0.0001 \\
\hline & 6.4 & 293.2010 & & 118.1520 & 89.1131 & & & & & \\
\hline \multirow[t]{2}{*}{8} & 6.5 & 247.1653 & 4.0246 & 114.1270 & 72.0802 & Leu & 0.0013 & Leu-Ser & 247.1658 & 0.0005 \\
\hline & 6.4 & 251.1899 & & 118.1522 & 76.1051 & & & & & \\
\hline \multirow[t]{2}{*}{9} & 7.0 & 281.1492 & 4.0256 & 164.1059 & 149.0831 & Tyr & 0.0016 & Tyr-Ala & 281.1501 & 0.0009 \\
\hline & 7.0 & 285.1748 & & 168.1317 & 151.0956 & & & & & \\
\hline \multirow[t]{2}{*}{10} & 7.1 & 289.1760 & 4.0250 & 114.1272 & 72.0803 & Leu & 0.0011 & Leu-Glu & 289.1763 & 0.0003 \\
\hline & 7.1 & 293.2010 & & 118.1521 & 76.1054 & & & & & \\
\hline \multirow[t]{2}{*}{11} & 7.4 & 231.1701 & 4.0252 & 114.1270 & 85.0881 & Ile & 0.0013 & Ile-Ala & 231.1709 & 0.0008 \\
\hline & 7.3 & 235.1953 & & 118.1521 & 89.1133 & & & & & \\
\hline \multirow[t]{2}{*}{12} & 8.1 & 247.1656 & 4.0252 & 102.0908 & 114.1275 & Thr & 0.0011 & Thr-Val & 247.1658 & 0.0002 \\
\hline & 7.8 & 251.1908 & & 106.1162 & 118.1524 & & & & & \\
\hline \multirow[t]{2}{*}{13} & 8.3 & 297.1448 & 4.0258 & 88.0751 & 138.1025 & Ser & 0.0011 & Ser-Tyr & 297.1450 & 0.0002 \\
\hline & 8.3 & 301.1706 & & 92.1002 & 142.1271 & & & & & \\
\hline \multirow[t]{2}{*}{14} & 8.4 & 231.1699 & 4.0254 & 114.127 & 72.0803 & Leu & 0.0013 & Leu-Ala & 231.1709 & 0.0010 \\
\hline & 8.3 & 235.1953 & & 118.152 & 76.1053 & & & & & \\
\hline \multirow[t]{2}{*}{15} & 8.9 & 281.1498 & 4.0255 & 72.0803 & 160.1120 & Ala & 0.0010 & Ala-Tyr & 281.1501 & 0.0003 \\
\hline & 8.8 & 285.1753 & & 76.1054 & 164.1367 & & & & & \\
\hline 16 & 9.2 & 324.1554 & 4.0255 & 115.0859 & 265.1181 & Asn & 0.0012 & Asn-Tyr & 324.1559 & 0.0005 \\
\hline & 9.2 & 328.1809 & & 119.1115 & 269.1437 & & & & & \\
\hline 17 & 9.6 & 217.1547 & 4.0250 & 114.1271 & 72.0803 & Leu & 0.0012 & Leu-Gly & 217.1552 & 0.0005 \\
\hline & 9.5 & 221.1797 & & 118.1523 & 76.1055 & & & & & \\
\hline 18 & 10.8 & 281.1496 & 4.0254 & 148.1116 & 133.0881 & Phe & 0.0010 & Phe-Ser & 281.1501 & 0.0005 \\
\hline & 10.7 & 285.1750 & & 152.1367 & 135.1006 & & & & & \\
\hline
\end{tabular}

${ }^{a}$ Product ion (i) error relative value in Table S4. ${ }^{b}$ Obtained using ChemDraw software. ${ }^{c}$ Difference between precursor ion and $[\mathrm{M}+\mathrm{H}]^{+}$. The same below. 


\begin{tabular}{|c|c|c|c|c|c|c|c|c|c|c|}
\hline \multirow{2}{*}{ No. } & \multirow{2}{*}{$\begin{array}{l}\mathrm{RT} \\
\text { / } \min \end{array}$} & \multirow{2}{*}{$\begin{array}{l}\text { Precursor } \\
\text { ions }\end{array}$} & \multirow{2}{*}{$\begin{array}{c}\Delta \mathrm{m} / \mathrm{z} \\
(\mathrm{z}=1)\end{array}$} & \multirow{2}{*}{$\begin{array}{l}\text { Product ions } \\
\text { (i) }\end{array}$} & \multirow{2}{*}{$\begin{array}{l}\text { Product ions } \\
\text { (ii) }\end{array}$} & \multicolumn{2}{|c|}{ Match of product ion } & \multicolumn{3}{|c|}{ Match of amino compound } \\
\hline & & & & & & AA & Error / Da & Compounds & {$[\mathrm{M}+\mathrm{H}]^{+}$} & Error / Da \\
\hline \multirow[t]{2}{*}{19} & 11.7 & 307.1654 & 4.0253 & 164.1065 & 149.0831 & Tyr & 0.0010 & Tyr-Pro & 307.1658 & 0.0004 \\
\hline & 11.6 & 311.1907 & & 168.1314 & 151.0952 & & & & & \\
\hline \multirow[t]{2}{*}{20} & 11.8 & 295.165 & 4.0254 & 148.1117 & 133.0884 & Phe & 0.0009 & Phe-Thr & 295.1658 & 0.0008 \\
\hline & 11.7 & 299.1904 & & 152.1366 & 135.1009 & & & & & \\
\hline \multirow[t]{2}{*}{21} & 12.8 & 243.1702 & 4.0257 & 100.1115 & & Val & 0.0011 & Val-Pro & 243.1709 & 0.0007 \\
\hline & 12.8 & 247.1959 & & 104.1366 & & & & & & \\
\hline \multirow[t]{2}{*}{22} & 13.4 & 323.1603 & 4.0257 & 148.1118 & 133.0885 & Phe & 0.0008 & Phe-Glu & 323.1607 & 0.0004 \\
\hline & 13.4 & 327.1860 & & 152.1366 & 135.1008 & & & & & \\
\hline \multirow[t]{2}{*}{23} & 13.7 & 217.1546 & 4.0252 & 58.0645 & & Gly & 0.0012 & Gly-Ile/-Leu & 217.1552 & 0.0006 \\
\hline & 13.6 & 221.1798 & & 62.0898 & & & & & & \\
\hline \multirow[t]{2}{*}{24} & 13.7 & 243.1704 & 2.0124 & 84.0810 & & Pro & 0.0003 & Pro-Leu & 243.1709 & 0.0005 \\
\hline & 13.6 & 245.1828 & & 86.0934 & & & & & & \\
\hline \multirow[t]{2}{*}{25} & 13.8 & 309.1809 & 4.0252 & 100.1116 & & Val & 0.0010 & Val-Tyr & 309.1814 & 0.0005 \\
\hline & 13.7 & 313.2061 & & 104.1367 & & & & & & \\
\hline \multirow[t]{2}{*}{26} & 13.9 & 247.1655 & 4.0249 & 88.0751 & & Ser & 0.0011 & Ser-Leu/-Ile & 247.1658 & 0.0003 \\
\hline & 13.9 & 251.1904 & & 92.1000 & & & & & & \\
\hline \multirow[t]{2}{*}{27} & 14.0 & 274.1763 & 4.0249 & 115.0863 & 215.1388 & Asn & 0.0008 & Asn-Ile/-Leu & 247.1767 & \\
\hline & 14.0 & 278.2012 & & 119.1111 & 219.1634 & & & & & \\
\hline \multirow[t]{2}{*}{28} & 13.4 & 289.1762 & 4.0250 & 130.0855 & 84.0802 & Glu & 0.0013 & Glu-Ile/-Leu & 289.1763 & 0.0001 \\
\hline & 14.4 & 293.2012 & & 134.1106 & 88.1052 & & & & & \\
\hline \multirow[t]{2}{*}{29} & 14.2 & 259.2019 & 4.0249 & 114.1271 & 85.0882 & Ile & 0.0012 & Ile-Val & 259.2022 & 0.0003 \\
\hline & 14.2 & 263.2268 & & 118.1522 & 89.1134 & & & & & \\
\hline \multirow[t]{2}{*}{30} & 14.5 & 231.1702 & 4.0253 & 72.0802 & & Ala & 0.0011 & Ala-Leu/-Ile & 231.1709 & 0.0007 \\
\hline & 14.5 & 235.1955 & & 76.1052 & & & & & & \\
\hline \multirow[t]{2}{*}{31} & 14.8 & 265.1548 & 4.0250 & 148.1115 & 102.0544 & Phe & 0.0011 & Phe-Ala & 265.1552 & 0.0004 \\
\hline & 14.8 & 269.1798 & & 152.1364 & 106.0793 & & & & & \\
\hline \multirow[t]{2}{*}{32} & 15.0 & 251.1390 & 4.0259 & 148.1106 & 133.0878 & Phe & 0.0020 & Phe-Gly & 251.1396 & 0.0006 \\
\hline & 14.9 & 255.1649 & & 152.1367 & 135.1007 & & & & & \\
\hline \multirow[t]{2}{*}{33} & 15.2 & 275.1603 & 4.0248 & 116.0702 & 98.0596 & Asp & 0.0010 & Asp-Leu/-Ile & 275.1607 & 0.0004 \\
\hline & 15.1 & 279.1851 & & 120.0953 & 102.0847 & & & & & \\
\hline 34 & 15.2 & 259.2014 & 4.0254 & 114.1269 & 72.0803 & Leu & 0.0014 & Leu-Val & 259.2022 & 0.0008 \\
\hline & 15.2 & 263.2268 & & 118.1521 & 76.1054 & & & & & \\
\hline 35 & 15.4 & 261.1809 & 4.0253 & 102.0907 & 84.0802 & Thr & 0.0012 & Thr-Ile & 261.1814 & 0.0005 \\
\hline & 15.3 & 265.2062 & & 106.1159 & 88.1052 & & & & & \\
\hline 36 & 15.8 & 323.1966 & 4.0254 & 114.1270 & 84.0803 & Ile & 0.0013 & Ile-Tyr & 323.1971 & 0.0005 \\
\hline & 15.8 & 327.2220 & & 118.1522 & 89.1131 & & & & & \\
\hline 37 & 15.8 & 373.1762 & 4.0255 & 164.1066 & 149.0835 & Tyr & 0.0009 & Tyr-Tyr & 373.1763 & 0.0001 \\
\hline & 15.8 & 377.2017 & & 168.1318 & 151.0959 & & & & & \\
\hline 38 & 16.1 & 251.1384 & 4.0256 & 58.0645 & 148.1117 & Gly & 0.0012 & Gly-Phe & 251.1396 & 0.0012 \\
\hline & 16.1 & 255.1640 & & 62.0897 & 152.1386 & & & & & \\
\hline
\end{tabular}




\begin{tabular}{|c|c|c|c|c|c|c|c|c|c|c|}
\hline \multirow{2}{*}{ No. } & \multirow{2}{*}{$\begin{array}{c}\mathrm{RT} \\
\text { / min }\end{array}$} & \multirow{2}{*}{$\begin{array}{l}\text { Precursor } \\
\text { ions }\end{array}$} & \multirow{2}{*}{$\begin{array}{c}\Delta \mathrm{m} / \mathrm{z} \\
(\mathrm{z}=1)\end{array}$} & \multirow{2}{*}{$\begin{array}{l}\text { Product ions } \\
\text { (i) }\end{array}$} & \multirow{2}{*}{$\begin{array}{l}\text { Product ions } \\
\text { (ii) }\end{array}$} & \multicolumn{2}{|c|}{ Match of product ion } & \multicolumn{3}{|c|}{ Match of amino compound } \\
\hline & & & & & & AA & Error / Da & Compounds & {$[\mathrm{M}+\mathrm{H}]^{+}$} & Error / Da \\
\hline \multirow[t]{2}{*}{39} & 16.1 & 261.1802 & 4.0253 & 102.0903 & & Thr & 0.0016 & Thr-Leu & 261.1814 & 0.0012 \\
\hline & 16.1 & 265.2055 & & 106.1157 & & & & & & \\
\hline \multirow[t]{2}{*}{40} & 16.2 & 281.1492 & 4.0257 & 88.0750 & & Ser & 0.0012 & Ser-Phe & 281.1501 & 0.0009 \\
\hline & 16.2 & 285.1749 & & 92.0999 & & & & & & \\
\hline \multirow[t]{2}{*}{41} & 16.5 & 308.1601 & 4.0256 & 115.0861 & 84.0438 & Asn & 0.0010 & Asn-Phe & 308.161 & 0.0009 \\
\hline & 16.5 & 312.1857 & & 119.1110 & 88.0690 & & & & & \\
\hline \multirow[t]{2}{*}{42} & 16.6 & 323.1966 & 4.0253 & 114.1272 & 72.0804 & Leu & 0.0011 & Leu-Tyr & 323.1971 & 0.0005 \\
\hline & 16.6 & 327.2219 & & 118.1522 & 76.1052 & & & & & \\
\hline \multirow[t]{2}{*}{43} & 16.6 & 322.1760 & 4.0245 & 129.1016 & 84.0803 & Gln & 0.0012 & Gln-Phe & 322.1767 & 0.0007 \\
\hline & 16.6 & 326.2005 & & 133.1270 & 88.1054 & & & & & \\
\hline \multirow[t]{2}{*}{44} & 16.8 & 265.1550 & 4.0251 & 72.0802 & 233.0926 & Ala & 0.0011 & Ala-Phe & 265.1552 & 0.0002 \\
\hline & 16.8 & 269.1801 & & 76.1054 & 223.1446 & & & & & \\
\hline \multirow[t]{2}{*}{45} & 16.8 & 277.1549 & 2.0130 & 84.0804 & 231.2001 & Pro & 0.0009 & Pro-Phe & 277.1552 & 0.0003 \\
\hline & 16.8 & 279.1679 & & 86.0929 & 233.1313 & & & & & \\
\hline \multirow[t]{2}{*}{46} & 16.9 & 293.1865 & 4.0249 & 148.1117 & 133.0883 & Phe & 0.0009 & Phe-Val & 293.1865 & 0.0000 \\
\hline & 16.9 & 297.2114 & & 152.1366 & 135.1010 & & & & & \\
\hline \multirow[t]{2}{*}{47} & 17.7 & 273.2173 & 4.0253 & 114.1271 & 85.0878 & Ile & 0.0012 & Ile-Ile & 273.2178 & 0.0005 \\
\hline & 17.7 & 277.2426 & & 118.1520 & 89.1127 & & & & & \\
\hline \multirow[t]{2}{*}{48} & 17.9 & 323.1959 & 4.0257 & 164.1063 & 149.0835 & Tyr & 0.0012 & Tyr-Leu/-Ile & 323.1971 & 0.0012 \\
\hline & 17.9 & 327.2216 & & 168.1313 & 151.0955 & & & & & \\
\hline \multirow[t]{2}{*}{49} & 18.4 & 295.1653 & 4.0254 & 102.0907 & 277.1544 & Thr & 0.0012 & Thr-Phe & 295.1658 & 0.0005 \\
\hline & 18.3 & 299.1907 & & 106.1157 & 281.1800 & & & & & \\
\hline \multirow[t]{2}{*}{50} & 18.6 & 273.2176 & 4.0248 & 114.1271 & 72.0801 & Leu & 0.0012 & Leu-Ile/-Leu & 273.2178 & 0.0002 \\
\hline & 18.6 & 277.2424 & & 118.1522 & 76.1053 & & & & & \\
\hline \multirow[t]{2}{*}{51} & 18.8 & 293.1863 & 4.0250 & 100.1115 & 85.0881 & Val & 0.0011 & Val-Phe & 293.1865 & 0.0002 \\
\hline & 18.7 & 297.2113 & & 104.1364 & 89.1130 & & & & & \\
\hline \multirow[t]{2}{*}{52} & 19.3 & 273.2172 & 4.0253 & 114.1270 & 85.0881 & Ile & 0.0013 & Ile-Leu & 273.2178 & 0.0006 \\
\hline & 19.3 & 277.2425 & & 118.1521 & 89.1132 & & & & & \\
\hline \multirow[t]{2}{*}{53} & 19.7 & 357.1813 & 4.0248 & 164.1065 & 149.083 & Tyr & 0.0010 & Tyr-Phe & 357.1814 & 0.0001 \\
\hline & 19.7 & 361.2061 & & 168.1315 & 151.0958 & & & & & \\
\hline 54 & 20.2 & 307.2022 & 4.0249 & 148.1114 & 133.0878 & Phe & 0.0012 & Phe-Ile & 307.2022 & 0.0000 \\
\hline & 20.1 & 311.2271 & & 152.1372 & 135.1013 & & & & & \\
\hline 55 & 20.1 & 291.1706 & 4.0251 & 148.1113 & 133.088 & Phe & 0.0013 & Phe-Pro & 291.1709 & 0.0003 \\
\hline & 20.1 & 295.1957 & & 152.1364 & 135.1007 & & & & & \\
\hline 56 & 21.0 & 307.2019 & 4.0252 & 114.1273 & 85.0884 & Ile & 0.0010 & Ile-Phe & 307.2022 & 0.0003 \\
\hline & 21.0 & 311.2271 & & 118.1524 & 89.1134 & & & & & \\
\hline 57 & 22.1 & 307.2021 & 4.0254 & 114.1270 & 72.0800 & Leu & 0.0013 & Leu-Phe & 307.2022 & 0.0001 \\
\hline & 22.1 & 311.2275 & & 118.1523 & 76.1055 & & & & & \\
\hline 58 & 23.5 & 307.2020 & 4.0255 & 148.1120 & 133.0883 & Phe & 0.0006 & Phe-Leu & 307.2022 & 0.0002 \\
\hline & 23.5 & 311.2275 & & 152.1368 & 135.1002 & & & & & \\
\hline
\end{tabular}

To be continued 
Part III. Other polypeptides (Identified number = 19)

\begin{tabular}{|c|c|c|c|c|c|c|c|c|c|c|}
\hline \multirow{2}{*}{ No. } & \multirow{2}{*}{$\begin{array}{l}\mathrm{RT} \\
/ \mathrm{min}\end{array}$} & \multirow{2}{*}{$\begin{array}{l}\text { Precursor } \\
\text { ions }\end{array}$} & \multirow{2}{*}{$\begin{array}{c}\Delta \mathrm{m} / \mathrm{z} \\
(\mathrm{z}=1)\end{array}$} & \multirow{2}{*}{$\begin{array}{l}\text { Product ions } \\
\text { (i) }\end{array}$} & \multirow{2}{*}{$\begin{array}{l}\text { Product ions } \\
\text { (ii) }\end{array}$} & \multicolumn{2}{|c|}{ Match of product ion } & \multicolumn{3}{|c|}{ Match of amino compound } \\
\hline & & & & & & AA & Error / Da & Compounds & {$[\mathrm{M}+\mathrm{H}]^{+}$} & Error / Da \\
\hline \multirow[t]{2}{*}{59} & 7.25 & 307.1685 & 4.0252 & 114.1272 & 72.0803 & Leu & 0.0011 & Leu-peptide & & \\
\hline & 7.21 & 311.1937 & & 118.1520 & 76.1050 & & & & & \\
\hline \multirow[t]{2}{*}{60} & 8.87 & 346.2337 & 4.0257 & 100.1116 & 114.1274 & Val & 0.0010 & Val-peptide & & \\
\hline & 8.83 & 350.2594 & & 104.1367 & 118.1522 & & & & & \\
\hline \multirow[t]{2}{*}{61} & 10.23 & 318.2016 & 4.0257 & 114.1270 & 58.0644 & Ile & 0.0013 & Ile-/Leu-peptid & & \\
\hline & 9.71 & 322.2273 & & 118.1525 & 62.0900 & & & e & & \\
\hline \multirow[t]{2}{*}{62} & 10.19 & 316.2231 & 4.0257 & 100.1117 & & Val & 0.0009 & Val-peptide & & \\
\hline & 10.12 & 320.2488 & & 104.1365 & & & & & & \\
\hline \multirow[t]{2}{*}{63} & 10.37 & 332.2176 & 4.0254 & 72.0802 & 185.1646 & Ala & 0.0011 & Ala-peptide & & \\
\hline & 10.33 & 336.2430 & & 76.1055 & 189.1899 & & & & & \\
\hline \multirow[t]{2}{*}{64} & 11.03 & 346.2336 & 4.0250 & 100.1115 & & Val & 0.0011 & Val-peptide & & \\
\hline & 11 & 350.2586 & & 104.1367 & & & & & & \\
\hline \multirow[t]{2}{*}{65} & 11.29 & 302.2068 & 4.0254 & 72.0803 & 185.1652 & Ala & 0.0010 & Ala-peptide & & \\
\hline & 11.22 & 306.2322 & & 76.1055 & 189.1901 & & & & & \\
\hline \multirow[t]{2}{*}{66} & 12.85 & 362.2282 & 4.0258 & 102.0910 & 215.1757 & Ser & 0.0009 & Ser-peptide & & \\
\hline & 12.72 & 366.2540 & & 106.1159 & 219.2001 & & & & & \\
\hline \multirow[t]{2}{*}{67} & 13.46 & 401.2071 & 8.0510 & 148.1122 & 192.1021 & Phe & 0.0004 & Phe-peptide & & \\
\hline & 13.39 & 409.2581 & & 152.1364 & 196.1277 & & & & & \\
\hline \multirow[t]{2}{*}{68} & 13.73 & 360.2496 & 4.0248 & 100.1117 & & Val & 0.0009 & Val-peptide & & \\
\hline & 13.68 & 364.2744 & & 104.1365 & & & & & & \\
\hline \multirow[t]{2}{*}{69} & 13.78 & 374.2282 & 4.0252 & 114.1275 & 85.0877 & Ile & 0.0008 & Ile-peptide & & \\
\hline & 13.78 & 378.2534 & & 118.1524 & & & & & & \\
\hline \multirow[t]{2}{*}{70} & 14.34 & 360.2489 & 4.0259 & 114.1271 & 84.0803 & Ile & 0.0012 & Ile-peptide & & \\
\hline & 14.32 & 364.2748 & & 118.1524 & 88.1056 & & & & & \\
\hline \multirow[t]{2}{*}{71} & 14.84 & 360.2492 & 4.0254 & 114.1272 & 72.082 & Leu & 0.0011 & Leu-peptide & & \\
\hline & 14.82 & 364.2746 & & 118.1525 & 76.1055 & & & & & \\
\hline \multirow[t]{2}{*}{72} & 15.24 & 302.2438 & 4.0256 & 114.1271 & 85.0882 & Ile & 0.0012 & Ile-peptide & & \\
\hline & 15.23 & 306.2694 & & 118.1524 & 89.1133 & & & & & \\
\hline \multirow[t]{2}{*}{73} & 16.23 & 390.2229 & 4.0248 & 102.0907 & 231.1335 & Thr & 0.0012 & Thr-Glu-Leu & 390.2240 & 0.0011 \\
\hline & 16.14 & 394.2477 & & 106.1157 & 235.1582 & & & & & \\
\hline \multirow[t]{2}{*}{74} & 17.65 & 290.1962 & 4.0251 & 116.0701 & 230.1747 & Asp & 0.0011 & Asp-peptide & & \\
\hline & 17.64 & 294.2213 & & 120.095 & 234.1996 & & & & & \\
\hline 75 & 17.89 & 344.2537 & 4.0258 & 100.1116 & 88.0751 & Val & 0.0010 & Val-peptide & & \\
\hline & 17.88 & 348.2795 & & 104.1368 & 92.1005 & & & & & \\
\hline 76 & 24.03 & 477.2349 & 6.0388 & 116.0701 & 417.2127 & Asp & 0.0011 & Asp-peptide & & \\
\hline & 23.98 & 483.2737 & & 120.0951 & 423.2538 & & & & & \\
\hline 77 & 45.39 & 480.3091 & 4.0255 & 72.0801 & 170.0574 & Ala & 0.0012 & Ala-peptide & & \\
\hline & 45.38 & 484.3346 & & 76.1055 & 174.0827 & & & & & \\
\hline
\end{tabular}

To be continued 
Part IV. Unknown amino compounds (Identified number = 77)

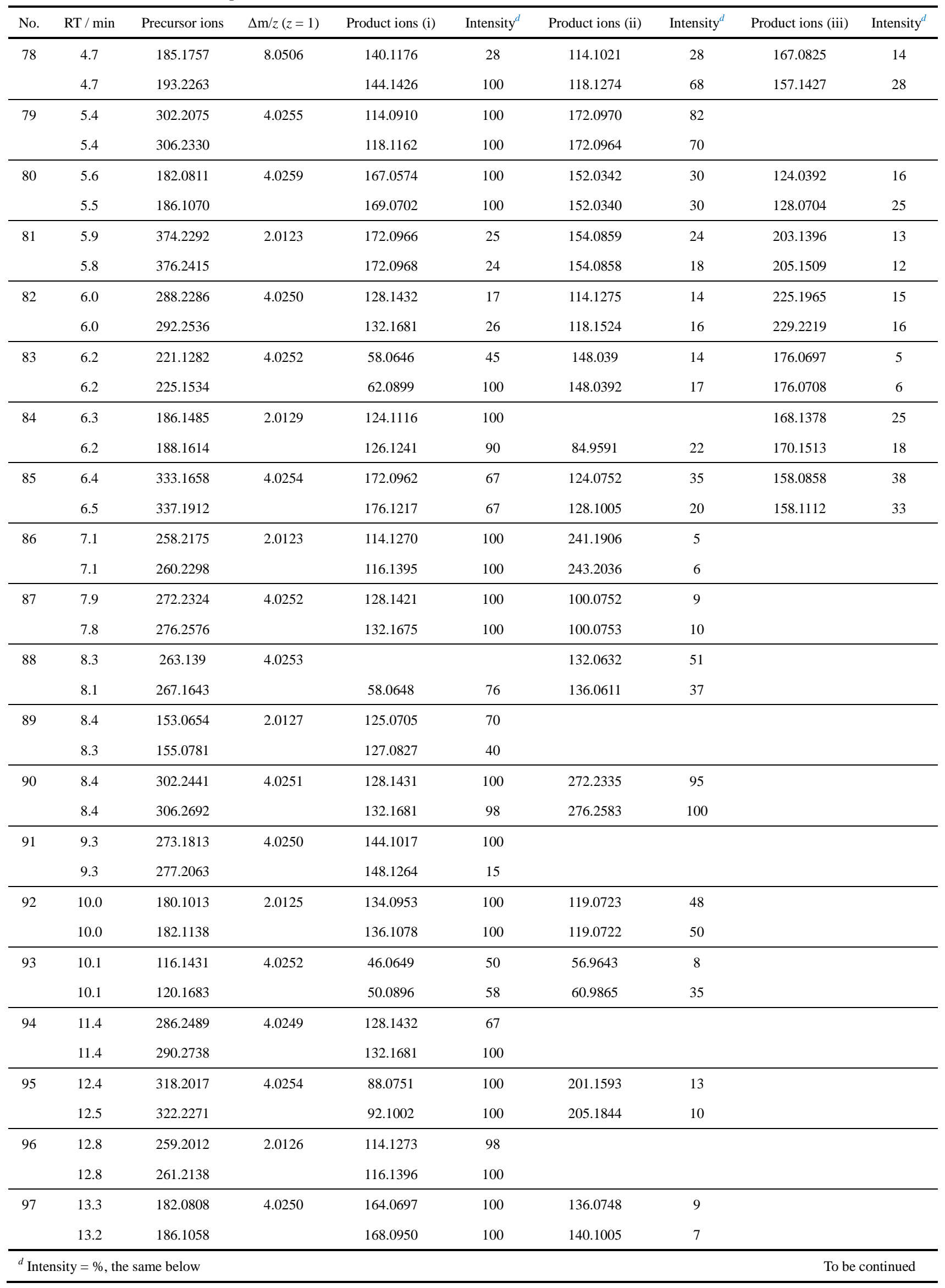




\begin{tabular}{|c|c|c|c|c|c|c|c|c|c|}
\hline No. & $\mathrm{RT} / \mathrm{min}$ & Precursor ions & $\Delta \mathrm{m} / \mathrm{z}(\mathrm{z}=1)$ & Product ions (i) & Intensity & Product ions (ii) & Intensity & Product ions (iii) & Intensity \\
\hline \multirow[t]{2}{*}{98} & 13.5 & 209.1043 & 4.0249 & 163.0987 & 100 & 147.1033 & 10 & & \\
\hline & 13.4 & 213.1292 & & 167.1239 & 100 & 151.1288 & 17 & & \\
\hline \multirow[t]{2}{*}{99} & 13.7 & 273.2172 & 4.0252 & 128.1427 & 85 & 100.1114 & 20 & 145.1696 & 20 \\
\hline & 13.7 & 277.2424 & & 132.1680 & 75 & 100.1117 & 20 & 149.1949 & 16 \\
\hline \multirow[t]{2}{*}{100} & 13.9 & 283.0250 & 4.0252 & 102.0373 & 50 & 134.0094 & 80 & & \\
\hline & 13.8 & 287.0502 & & 106.0621 & 100 & 138.0342 & 80 & & \\
\hline \multirow[t]{2}{*}{101} & 14.0 & 148.1116 & 4.0252 & 91.0534 & 100 & 133.0882 & 100 & & \\
\hline & 14.0 & 152.1368 & & 91.0529 & 40 & 135.1003 & 60 & & \\
\hline \multirow[t]{2}{*}{102} & 14.1 & 279.1340 & 6.0381 & 102.0544 & 100 & 162.0546 & 13 & 233.1278 & 5 \\
\hline & 14.0 & 285.1721 & & 106.0796 & 100 & 164.0674 & 10 & 239.1657 & 5 \\
\hline \multirow[t]{2}{*}{103} & 14.3 & 298.0926 & 4.0251 & 164.0701 & 100 & 182.0815 & 14 & & \\
\hline & 14.2 & 302.1177 & & 168.0951 & 100 & 186.1065 & 12 & & \\
\hline \multirow[t]{2}{*}{104} & 14.6 & 307.1688 & 4.0253 & 84.0803 & 100 & 243.1704 & 60 & 215.1391 & 55 \\
\hline & 14.6 & 311.1941 & & 88.1054 & 75 & & & 219.1642 & 45 \\
\hline \multirow[t]{2}{*}{105} & 14.8 & 311.1102 & 4.0253 & 205.0642 & 78 & 102.0368 & 100 & 71.0725 & 68 \\
\hline & 14.8 & 315.1355 & & 209.0888 & 100 & 106.0616 & 73 & 75.0975 & 75 \\
\hline \multirow[t]{2}{*}{106} & 15.1 & 455.2873 & 4.0249 & 86.0959 & 100 & 326.2085 & 15 & & \\
\hline & 15.1 & 459.3122 & & 90.1213 & 100 & 330.2341 & 18 & & \\
\hline \multirow[t]{2}{*}{107} & 15.2 & 435.1885 & 6.0385 & 58.0648 & 41 & 146.0599 & 32 & 302.1510 & 18 \\
\hline & 15.1 & 441.2270 & & 62.0898 & 75 & 148.0731 & 17 & 308.1886 & 17 \\
\hline \multirow[t]{2}{*}{108} & 15.3 & 186.1488 & 2.0127 & 168.1382 & 100 & 95.0853 & 58 & & \\
\hline & 15.3 & 188.1615 & & 170.1508 & 100 & 95.0852 & 53 & & \\
\hline \multirow[t]{2}{*}{109} & 15.5 & 385.3180 & 4.0253 & 128.1429 & 42 & 114.0909 & 20 & & \\
\hline & 15.5 & 389.3433 & & 132.1682 & 45 & 114.0909 & 22 & & \\
\hline \multirow[t]{2}{*}{110} & 15.7 & 340.2962 & 2.0128 & 114.1272 & 8 & 213.2321 & 8 & & \\
\hline & 15.7 & 342.309 & & 116.1400 & 6 & 215.2444 & 8 & & \\
\hline \multirow[t]{2}{*}{111} & 15.9 & 358.3061 & 4.0250 & 128.1424 & 100 & 86.0957 & 10 & 196.1325 & 7 \\
\hline & 15.9 & 362.3311 & & 132.1677 & 100 & 86.0957 & 10 & 196.1321 & 7 \\
\hline \multirow[t]{2}{*}{112} & 16.1 & 372.2854 & 4.0253 & 128.1430 & 100 & 100.0752 & 28 & 254.2233 & 4 \\
\hline & 16.1 & 376.3107 & & 132.1674 & 100 & 100.0749 & 27 & 259.2310 & 6 \\
\hline \multirow[t]{2}{*}{113} & 16.1 & 283.1650 & 4.0258 & 74.0593 & 28 & 221.1648 & 22 & & \\
\hline & 16.0 & 287.1908 & & 78.0847 & 38 & 225.1894 & 73 & & \\
\hline \multirow[t]{2}{*}{114} & 16.1 & 403.1977 & 4.0251 & 84.0801 & 100 & 300.1702 & 2 & & \\
\hline & 16.1 & 407.2228 & & 86.0927 & 100 & 304.1978 & 4 & & \\
\hline \multirow[t]{2}{*}{115} & 16.5 & 362.2070 & 6.0369 & 100.1113 & 100 & 85.0872 & 10 & & \\
\hline & 16.5 & 368.2439 & & 104.1364 & 100 & 89.1128 & 4 & & \\
\hline \multirow[t]{2}{*}{116} & 17.0 & 389.1383 & 4.0255 & 205.0639 & 100 & 159.0762 & 50 & 102.0370 & 38 \\
\hline & 17.0 & 393.1638 & & 209.0894 & 100 & 163.1012 & 70 & 106.0620 & 20 \\
\hline \multirow[t]{2}{*}{117} & 17.0 & 465.2360 & 6.0375 & 102.0910 & 100 & 346.1773 & 5 & & \\
\hline & 16.9 & 471.2735 & & 106.1162 & 100 & 252.2151 & 5 & & \\
\hline \multirow[t]{2}{*}{118} & 17.1 & 326.2803 & 2.0127 & 114.1273 & 65 & 182.1897 & 22 & 258.2175 & 11 \\
\hline & 17.1 & 328.2930 & & 116.1398 & 45 & 184.2022 & 16 & 260.2308 & 15 \\
\hline
\end{tabular}




\begin{tabular}{|c|c|c|c|c|c|c|c|c|c|}
\hline \multicolumn{10}{|c|}{ To be continued } \\
\hline No. & $\mathrm{RT} / \mathrm{min}$ & Precursor ions & $\Delta \mathrm{m} / \mathrm{z}(\mathrm{z}=1)$ & Product ions (i) & Intensity & Product ions (ii) & Intensity & Product ions (iii) & Intensity \\
\hline \multirow[t]{2}{*}{119} & 17.6 & 372.2857 & 2.0125 & 114.0910 & 40 & 354.1890 & 6 & & \\
\hline & 17.6 & 374.2982 & & 116.1400 & 46 & 356.2073 & 4 & & \\
\hline \multirow[t]{2}{*}{120} & 17.8 & 268.1646 & 2.0123 & 142.0859 & 100 & 250.1423 & 25 & 96.0806 & 18 \\
\hline & 17.8 & 270.1769 & & 144.0986 & 100 & 252.1948 & 5 & 98.0927 & 33 \\
\hline \multirow[t]{2}{*}{121} & 17.8 & 372.3216 & 4.0254 & 128.1428 & 57 & & & & \\
\hline & 17.8 & 376.3470 & & 132.1677 & 53 & & & & \\
\hline \multirow[t]{2}{*}{122} & 17.9 & 386.3016 & 4.0248 & 128.1426 & 40 & 255.2062 & 5 & & \\
\hline & 17.9 & 390.3264 & & 132.1676 & 40 & 259.2327 & 5 & & \\
\hline \multirow[t]{2}{*}{123} & 17.9 & 399.3332 & 4.0251 & 128.1429 & 40 & 255.1725 & 6 & & \\
\hline & 17.9 & 403.3583 & & 132.1677 & 40 & 259.2308 & 4 & & \\
\hline \multirow[t]{2}{*}{124} & 18.0 & 320.2065 & 2.0122 & 242.1747 & 88 & 260.1848 & 90 & 86.0591 & 13 \\
\hline & 18.0 & 322.2187 & & 244.1877 & 100 & 262.1981 & 85 & 88.0722 & 19 \\
\hline \multirow[t]{2}{*}{125} & 18.1 & 361.1627 & 2.0125 & 164.0706 & 23 & 258.1247 & 7 & & \\
\hline & 18.1 & 363.1752 & & 166.0832 & 15 & 260.1362 & 5 & & \\
\hline \multirow[t]{2}{*}{126} & 18.2 & 233.1285 & 4.0250 & 102.0541 & 100 & 146.0593 & 52 & 188.0698 & 38 \\
\hline & 18.2 & 237.1535 & & 106.0793 & 100 & 146.0593 & 55 & 188.0699 & 48 \\
\hline \multirow[t]{2}{*}{127} & 18.5 & 498.4019 & 4.0251 & 128.1426 & 23 & 210.1484 & 10 & 371.3386 & 5 \\
\hline & 18.5 & 502.4270 & & 132.1676 & 22 & 210.1484 & 10 & 375.3628 & 5 \\
\hline \multirow[t]{2}{*}{128} & 18.7 & 250.1437 & 4.0258 & 128.1429 & 100 & 186.1278 & 28 & 204.1380 & 20 \\
\hline & 18.6 & 254.1695 & & 132.0956 & 100 & 190.1527 & 50 & 208.1640 & 47 \\
\hline \multirow[t]{2}{*}{129} & 18.9 & 286.0604 & 4.0252 & 102.0547 & 100 & 180.0146 & 28 & & \\
\hline & 18.8 & 290.0856 & & 106.0795 & 100 & 184.0397 & 48 & & \\
\hline \multirow[t]{2}{*}{130} & 19.2 & 485.3702 & 4.0259 & 128.1430 & 20 & 371.3389 & 10 & & \\
\hline & 19.2 & 489.3961 & & 132.1676 & 20 & 375.3647 & 12 & & \\
\hline \multirow[t]{2}{*}{131} & 19.8 & 247.1442 & 6.0374 & 216.1016 & 100 & 120.0803 & 98 & & \\
\hline & 19.7 & 253.1816 & & 220.1267 & 100 & 124.1055 & 80 & & \\
\hline \multirow[t]{2}{*}{132} & 19.7 & 297.1444 & 4.0258 & 251.1387 & 100 & 207.1490 & 15 & 110.0959 & 18 \\
\hline & 19.7 & 301.1702 & & 255.1645 & 100 & 211.1757 & 12 & 114.1218 & 16 \\
\hline \multirow[t]{2}{*}{133} & 19.9 & 485.3712 & 2.0120 & 114.1273 & 19 & 210.1492 & 9 & & \\
\hline & 19.9 & 487.3832 & & 116.1398 & 17 & 210.149 & 12 & & \\
\hline \multirow[t]{2}{*}{134} & 20.2 & 499.3860 & 4.0252 & 128.1429 & 19 & 210.1487 & 8 & 371.3394 & 3 \\
\hline & 20.2 & 503.4112 & & 132.1681 & 17 & 210.1486 & 8 & 375.3639 & 2 \\
\hline \multirow[t]{2}{*}{135} & 20.4 & 318.2275 & 2.0127 & 300.2172 & 62 & 182.1541 & 21 & 144.1017 & 18 \\
\hline & 20.4 & 320.2402 & & 302.2298 & 52 & 184.1670 & 17 & 146.1140 & 18 \\
\hline \multirow[t]{2}{*}{136} & 20.5 & 429.3078 & 2.0127 & 86.0959 & 100 & 312.2289 & 18 & & \\
\hline & 20.5 & 431.3205 & & 88.1083 & 100 & 314.2407 & 23 & & \\
\hline \multirow[t]{2}{*}{137} & 20.7 & 340.2963 & 4.0246 & 128.1430 & 43 & 168.1384 & 37 & 196.1330 & 30 \\
\hline & 20.7 & 344.3209 & & 132.1671 & 40 & 168.1378 & 40 & 196.1337 & 27 \\
\hline \multirow[t]{2}{*}{138} & 21.0 & 233.1279 & 4.0255 & 202.0853 & 100 & 160.0751 & 78 & 132.0803 & 63 \\
\hline & 21.0 & 237.1534 & & 204.0977 & 100 & 162.0878 & 85 & 134.0928 & 72 \\
\hline
\end{tabular}




\begin{tabular}{|c|c|c|c|c|c|c|c|c|c|}
\hline No. & $\mathrm{RT} / \mathrm{min}$ & Precursor ions & $\Delta \mathrm{m} / \mathrm{z}(\mathrm{z}=1)$ & Product ions (i) & Intensity & Product ions (ii) & Intensity & Product ions (iii) & Intensity \\
\hline \multirow[t]{2}{*}{139} & 21.0 & 202.0861 & 2.0126 & 160.0757 & 100 & 132.0805 & 95 & 117.0570 & 48 \\
\hline & 21.0 & 204.0987 & & 162.0881 & 100 & 134.0929 & 90 & 115.0537 & 53 \\
\hline \multirow[t]{2}{*}{140} & 22.1 & 245.1286 & 2.0129 & 158.0957 & 100 & 88.0387 & 23 & & \\
\hline & 22.1 & 247.1415 & & 158.0960 & 100 & 90.0514 & 25 & & \\
\hline \multirow[t]{2}{*}{141} & 22.6 & 304.1660 & 6.0372 & 58.0647 & 100 & 144.0803 & 18 & & \\
\hline & 22.6 & 310.2032 & & 62.0899 & 100 & 146.0936 & 10 & & \\
\hline \multirow[t]{2}{*}{142} & 23.0 & 376.1870 & 6.0368 & 130.0862 & 100 & 84.0801 & 20 & & \\
\hline & 23.0 & 382.2238 & & 134.1108 & 100 & 88.1055 & 20 & & \\
\hline \multirow[t]{2}{*}{143} & 23.4 & 342.3119 & 4.0252 & 128.1429 & 60 & 170.1573 & 30 & & \\
\hline & 23.4 & 346.3371 & & 132.1678 & 65 & 170.1534 & 31 & & \\
\hline \multirow[t]{2}{*}{144} & 23.7 & 362.1714 & 6.0372 & 116.0704 & 100 & 202.0864 & 20 & & \\
\hline & 23.6 & 368.2086 & & 120.0951 & 100 & 204.0988 & 20 & & \\
\hline \multirow[t]{2}{*}{145} & 25.2 & $363.2805^{e}$ & 2.0127 & 128.1429 & 78 & & & & \\
\hline & 25.2 & $365.2932^{e}$ & & 132.1681 & 87 & & & & \\
\hline \multirow[t]{2}{*}{146} & 25.6 & 176.0707 & 2.0124 & 130.0647 & 50 & 103.0537 & 40 & 158.0599 & 30 \\
\hline & 25.6 & 178.0831 & & 132.0768 & 56 & 105.0663 & 40 & 160.0722 & 30 \\
\hline \multirow[t]{2}{*}{147} & 26.2 & 371.2551 & 2.0120 & 98.0962 & 100 & 325.2494 & 75 & 307.2386 & 30 \\
\hline & 26.2 & 373.2671 & & 100.1085 & 100 & 327.262 & 56 & 309.252 & 26 \\
\hline \multirow[t]{2}{*}{148} & 26.7 & 385.2704 & 4.0249 & 339.2643 & 100 & 266.2126 & 20 & & \\
\hline & 26.7 & 389.2953 & & 343.2898 & 100 & 266.2122 & 20 & & \\
\hline \multirow[t]{2}{*}{149} & 27.4 & 691.5133 & 2.0121 & 112.1126 & 3 & 673.5037 & 3 & & \\
\hline & 27.4 & 693.5254 & & 114.1250 & 3 & 675.4820 & 15 & & \\
\hline \multirow[t]{2}{*}{150} & 30.0 & 342.3115 & 4.0255 & 128.1428 & 50 & 198.1484 & 13 & & \\
\hline & 30.0 & 346.3370 & & 132.1671 & 45 & 198.1490 & 15 & & \\
\hline \multirow[t]{2}{*}{151} & 30.2 & 305.1135 & 2.0125 & 144.0803 & 100 & 202.0861 & 20 & 259.1080 & 14 \\
\hline & 30.2 & 307.1260 & & 146.0928 & 100 & 204.0988 & 26 & 261.1199 & 20 \\
\hline \multirow[t]{2}{*}{152} & 31.0 & 568.4812 & 4.0253 & 128.1432 & 9 & 198.1492 & 3 & 371.3394 & 3 \\
\hline & 30.9 & 572.5065 & & 132.1685 & 10 & 198.1497 & 4 & 375.3654 & 4 \\
\hline \multirow[t]{2}{*}{153} & 33.8 & 390.2856 & 4.0250 & 102.0544 & 80 & 372.2749 & 55 & 272.2580 & 18 \\
\hline & 33.8 & 394.3106 & & 106.0795 & 85 & 376.3003 & 40 & 276.2831 & 15 \\
\hline \multirow[t]{2}{*}{154} & 34.0 & 285.1233 & 2.0128 & 164.0704 & 100 & 122.0599 & 40 & 136.0752 & 32 \\
\hline & 34.0 & 287.1361 & & 166.0827 & 100 & 122.0592 & 50 & 138.0877 & 25 \\
\hline
\end{tabular}

${ }^{e}$ No. $145, z=2$. 